Microstructural analysis of Ta-containing NiCoCrAIY bond coats deposited by HVOF on different Ni-based superalloys

by

A.G. Mora-García ${ }^{\mathrm{a}, \mathrm{c}}$, H. Ruiz-Luna ${ }^{\mathrm{b}}$, M. Mosbacher
J. R. Popp
J. Muñoz-Saldaña ${ }^{\mathrm{a}, \mathrm{d}}$.

${ }^{a}$ Centro de Investigación y de Estudios Avanzados del I.P.N. Unidad Queretaro.

${ }^{\mathrm{b}}$ Conacyt - Universidad Autónoma de Zacatecas.

${ }^{c}$ Bayreuth University, Institute for Metals and Alloys.

${ }^{\mathrm{d}}$ German Aerospace Center, Institute of Materials Research. 


\title{
Microstructural analysis of Ta-containing NiCoCrAIY bond coats deposited by HVOF on different Ni-based superalloys
}

\author{
A.G. Mora-García ${ }^{\text {a,c }}$, H. Ruiz-Luna ${ }^{\mathrm{b}}$, M. Mosbacher ${ }^{\mathrm{c}}$, R. Popp ${ }^{\mathrm{c}}$, U. Schulz ${ }^{\mathrm{d}}$, U. Glatzel ${ }^{\mathrm{c}}$, \\ J. Muñoz-Saldaña ${ }^{\mathrm{a}, \mathrm{d}, *}$.

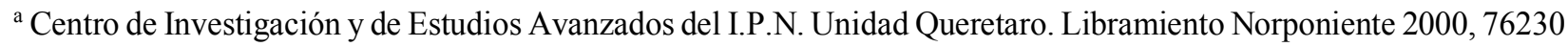 \\ Queretaro, Mexico.almamora@cinvestav.mx;jmunoz@cinvestav.mx. \\ b Conacyt - Universidad Autónoma de Zacatecas. Av. Ramon Lopez Velarde 801, 98000 Zacatecas, Mexico. \\ hruizlu@conacyt.mx. \\ c Bayreuth University, Institute for Metals and Alloys. Ludwig-Thoma-Straße 36b, 95447 Bayreuth, Germany. \\ Alma.Mora-Garcia@uni-bayreuth.de; Mike.Mosbacher@uni-bayreuth.de; $\quad$ Robert.Popp@uni-bayreuth.de; \\ Uwe.Glatzel@uni-bayreuth.de. \\ d German Aerospace Center, Institute of Materials Research. Linder Höhe, 51147 Cologne, Germany. \\ uwe.schulz@dlr.de.
}

\begin{abstract}
The microstructural and chemical evolution after different processing steps of Ta-containing NiCoCrAlY bond coats (BC) sprayed by high velocity oxy-fuel on Ni-base superalloy (SA) substrates, top-coated with 7YSZ and furnace cycled at $1100{ }^{\circ} \mathrm{C}$ focusing along the $\mathrm{BC} / \mathrm{SA}$ interfaces is presented. Three superalloys were selected considering their Ta content relative to that within the BC: a) no Ta in the superalloy composition (IN100) and either b) similar or c) higher Ta content with respect to the BC (M247LC SX and CMSX-4, respectively). The processing conditions were as-sprayed, as-annealed, after EB-PVD deposition of a 7YSZ top coat, and after furnace cyclic tests $\left(1100{ }^{\circ} \mathrm{C} / 120 \mathrm{~h}\right)$. The evolution of chemical composition after the different process steps are presented that include a normalization criteria to a Ni-Al-Cr system, elemental profiles as well as Weibull distribution plots of minor containing elements such as $\mathrm{Ti}, \mathrm{Ta}, \mathrm{Mo}$, or $\mathrm{W}$ at the BC/SA interface. The effect of Ta was activated in some coated substrates by the presence of $\mathrm{Ti}$ and $\mathrm{C}$ in the superalloy consisting of inward Ta-diffusion, trapping of outward diffusing $\mathrm{Ti}$ and the subsequent formation of ( $\mathrm{Ta}, \mathrm{Ti}$ )-rich carbides in the $\mathrm{BC}$ avoiding possible segregation effects as titanium oxide in the oxide scale.
\end{abstract}

Keywords: Ta-containing NiCoCrAlY coating; HVOF deposition; Ni-based superalloys; elemental diffusion.

* Georg Forster Humboldt fellow and corresponding author (e-mail: jmunoz@cinvestav.mx; phone:+52 (442) 211 9924). 


\section{Introduction}

Advanced coatings are a necessity to protect metallic components exposed to harsh environments, e.g., for components used in the aeronautical or stationary gas turbines for power generation. For instance, thermal barrier coatings systems (TBC) have proven effectiveness in protecting metallic parts against extreme operating conditions, which are characterized by structural loads, oxidizing and corrosive atmospheres as well as thermal cycles at high temperatures [1-7]. TBC systems consist of a low thermal conductivity top coat (TC), typically yttria-stabilized zirconia (YSZ) protecting a nickel-based superalloy substrate (SA). The TC is bonded to the SA by an aluminumcontaining bond coat (BC), which can form a thermally grown oxide (TGO), preferably $\alpha-\mathrm{Al}_{2} \mathrm{O}_{3}$. Depending on the BC fabrication process, they are classified as diffusion- or overlay-types. A typical overlay $\mathrm{BC}$ is a MCrAlX alloy, where $\mathrm{M}$ stands for nickel, cobalt or both and $\mathrm{X}$ is usually yttrium and is commonly deposited by either sputtering or thermal spray processes. The latter are typically air plasma spraying (APS), low pressure plasma spraying (LPPS) or vacuum plasma spraying (VPS) and more recently high velocity oxy-fuel (HVOF), which has been used in order to yield high density coatings [8,9]. The selected composition depends on the BC application and operating conditions. NiCoCrAlY-type alloys are widely employed because they exhibit a higher oxidation resistance than NiCrAlYs and better corrosion resistance (e.g., sulfidation) than CoCrAlYs [10]. The microstructure of NiCoCrAlY coatings consists mainly of $\gamma$-Ni and $\beta$-NiAl phases, with their relative volume fractions dependent on the chemical composition. The $\gamma-\mathrm{Ni}$ phase is a face-centered cubic solid solution of $\mathrm{Ni}, \mathrm{Cr}$, and $\mathrm{Co}$, whereas the $\beta$-phase is an ordered $\mathrm{NiAl}$ intermetallic that crystallizes in a primitive cubic $\mathrm{CsCl}(\mathrm{B} 2)$ structure $[1,11,12] \cdot \gamma^{\prime}-\mathrm{Ni}_{3} \mathrm{Al}$ may also be observed as a result of Al depletion of the $\beta$-NiAl phase [1]. However, novel NiCoCrAlYtype coatings modified with either reactive (Hf, Y, Zr) or refractory elements (Re, Ta), among others have been widely studied because of their higher oxidation resistance. For instance, Hf, Re, 
$\mathrm{Pt}$, or Ta have been included in the chemical composition of bond coats to promote the formation of a slow growing $\alpha-\mathrm{Al}_{2} \mathrm{O}_{3}$ scale and to improve the thermo-mechanical stability of the $\mathrm{BC}$ [1315]. Moreover, it has been reported that additions of Ta to NiCoCrAlY coatings modify the microstructure compared with a non-Ta-containing NiCoCrAlY coating [14] and reduce the oxidation kinetics, irrespective of the coating fabrication technique (e.g. HVOF vs VPS) [14]. However, even when improvements in oxidation resistance are reported in that work, they are not directly associated to microstructure changes in the coating. The only reported effect about the advantages of Ta-additions in NiCoCrAlY-bond coats is to reduce the chemical activity and thus the diffusion rate of $\mathrm{Ti}$ from specific superalloys by trapping Ti to form stable (Ta,Ti)-carbides [16-19]. Overlay bond coats also have strong chemical interaction with the superalloy substrate under cyclic conditions at high temperature and thus diffusion processes strongly depend on the composition of the superalloy [20]. For instance, it is well known that, the presence of elements such as Ti in SA's is beneficial because, in the case of Ti, it promotes the formation of the ordered $\gamma^{\prime}$ phase, which in fact confers strength to the superalloy [21]. However, it has been claimed that in the bond coat, the presence of $\mathrm{Ti}$ is detrimental due to the formation of oxides $\left(\mathrm{TiO}_{2}\right)$ and thus less protective scale than in the case of pure $\alpha-\mathrm{Al}_{2} \mathrm{O}_{3}$ [16-19]. $\mathrm{TiO}_{2}$ inclusions are formed as particles within the $\alpha-\mathrm{Al}_{2} \mathrm{O}_{3}$ scale causing microcracks which induce the scale spallation. Moreover, the fast diffusion of $\mathrm{Ti}$ causes the incorporation of $\mathrm{Ti}^{4+}$ ions into the scale increasing the concentration of aluminum vacancies or oxygen interstitials which in fact increases the formation kinetics of $\alpha$ $\mathrm{Al}_{2} \mathrm{O}_{3}$ [20]. Thus, the addition of refractory elements, such as Ta to NiCoCrAlY coatings have potential for future development on TBC systems. However, diffusion processes of Ta from NiCoCrAlYTa commercial bond coats and its interaction with other elements from different superalloys have been barely reported. Previous reports have been focused on oxidation effects (e.g., weight gain, lifetime under furnace cycling tests) as well as oxide scales and bond coat 
characteristics [14,22-24]. Moreover, few investigations have been conducted to understand the interplay of Ta with Ti, Hf, Re, among other elements from the used superalloys, and the way it affects the microstructure and diffusion phenomena between the bond coat and the substrate, especially at their interface [25-27]. In this contribution, the effect of the chemical composition of IN100, CMSX-4 and M247LC SX superalloys on the microstructural and chemical evolution of a NiCoCrAlYTa BC through different processing stages and thermal cycling tests is presented and discussed. These superalloys were selected to study three cases relative to Ta-content with respect to the BC: a) no Ta in the superalloy composition (IN100) and either b) similar or c) higher Ta content with respect to the BC (M247LC-SX and CMSX-4, respectively).

\section{Material and methods}

Commercial NiCoCrAlYTa powder (Amdry 997, Oerlikon Metco) was utilized to deposit thermally-sprayed bond coats on three different Ni-based superalloys. Rectangular flat plates of $18 \times 12 \times 2 \mathrm{~mm}$ were used as substrates, consisting either of a commercial polycrystalline IN100 and CMSX-4 single crystal superalloys as well as M247LC SX, processed from its commercial condition to a single crystal in the metals and alloys department, University of Bayreuth (LMWUBayreuth). Before deposition, the substrates were cleaned by abrasive grit blasting using alumina particles ANSI G-24. Subsequently, bond coats were manufactured by high velocity oxy-fuel (HVOF) thermal spray process using a Diamond Jet 2700 spraying gun from Oerlikon Metco, which is manipulated with a 6-axis robot arm (KRC2, Kuka) from the thermal spray facilities of CENAPROT national laboratory. The parameters for BC deposition were chosen from a study reported elsewhere based on a design of experiments methodology as well as statistical analysis of variance [28]. The used parameters for HVOF Ta-containing NiCoCrAlY bond coats deposition are given in Table I. The surface of the as-sprayed bond coats was smoothed in two steps to reach 
an adequate roughness for future application of the ceramic top coat. The first step consisted of a coarse grinding by using an oscillating machine with silicon carbide powder 400 [P800] reaching a roughness $R_{a}$ from $\sim 7 \mu \mathrm{m}$ to $\sim 1 \mu \mathrm{m}$. As a second step, a shot peening process with yttria balls is carried out to densify the bond coat surface and to promote the formation of an alumina scale during the subsequent ceramic top coat deposition. Thereafter, in order to activate the elemental diffusion between SA substrates and $\mathrm{BC}$, the specimens were annealed at $1080{ }^{\circ} \mathrm{C}$ for $4 \mathrm{~h}$ in vacuum $\left(p_{O_{2}}<\right.$ $10^{-5}$ mbar). After this treatment, the specimens were coated with $7 \mathrm{wt} \%$ yttria-stabilized zirconia by electron beam physical vapor deposition (EB-PVD) technique at DLR under well-established parameters in a semi-industrial $150 \mathrm{~kW}(40 \mathrm{kV})$ dual-source jumping beam (Ardenne Anlagentechnik) EB-PVD coater. After this experimental step the samples are considered "ascoated".

As-coated TBC samples were exposed to cyclic oxidation in air at $1100^{\circ} \mathrm{C}$ in the DLR furnace for cycling testing (FCT). The oxidation treatment was performed for $120 \mathrm{~h}$ in a bottom-drop thermal cycle furnace. One cycle includes $45 \mathrm{~min}$ of heating at $1100{ }^{\circ} \mathrm{C}$ followed by $15 \mathrm{~min}$ of forced aircooling. The microstructure of powder particles, superalloys, and $\mathrm{BC}+\mathrm{SA}$ systems was analyzed at LMW-UBayreuth by scanning electron microscopy (1540EsB Cross Beam, Zeiss) adapted with an energy dispersive X-ray detector (Noran System Six EDX-System, Thermo) to evaluate the chemical composition. The chemical composition of the SA/BC systems was obtained from EDS measurements of areas (approx. $12 \mu \mathrm{m}^{2}$ ) from several zones along the cross sections, covering the matrix and in some cases multiphase zones, excluding the carbides, pores and internal oxides. The data was normalized to a Ni-Al-Cr System following the site preference criteria of transition metals, reported by Jiang [29].

Size distribution of the spray powder was measured in a laser diffraction sensor for particles in the range of 0.1 to $875 \mu \mathrm{m}$ (HELOS/BR-OM, Sympatec). The crystalline structure of the powder and 
bond coats was characterized by $\mathrm{X}$-ray diffraction using a Bragg-Brentano geometry with $\mathrm{Cu}-\mathrm{K}_{\alpha \mathrm{I}}$ radiation separated from $\mathrm{K}_{\alpha \mathrm{II}}$ with a monochromator, a step size of $0.02^{\circ}$, and step time of $0.5 \mathrm{~s}$ (D8 Discover, Bruker AXS). Additionally, EBSD analysis was carried out to confirm the presence of carbides and topologically close-packed phases, which were observed after annealing treatment and thermal cyclic oxidation. Cross-sectional micrographs, recorded by scanning electron microscopy were processed by image analysis (ImageJ software) to determine porosity level in the bond coats.

\section{Results and discussion}

\subsection{Raw materials}

The microstructural characteristics of the powder for HVOF deposition and of the substrates are essential to understand the diffusion effects occurring at different processing stages of the TBC systems as well as after thermal cyclic oxidation. The microstructural characteristics of the asreceived Ta-containing NiCoCrAlY powder are shown in Figure 1.

The observed morphology of Figure 1a confirmed spherical-shaped particles, typically from an atomization process. The size distribution is in the range from 6 to $60 \mu \mathrm{m}$, with an average diameter of $25 \mu \mathrm{m}$ and size distribution described by $d_{10}=11 \mu \mathrm{m}, d_{50}=23 \mu \mathrm{m}$ and $d_{90}=37 \mu \mathrm{m}$ (Figure 1b). Figure 1c shows the microstructure revealed by fine polishing of a powder particle cross section. The brighter and darker contrasts show the typical dendritic microstructure as result of the powder production process. This microstructure consists of a $\beta$ phase, which is Al-rich immersed in a Ni-rich $\gamma$ phase matrix. The X-ray diffraction patterns, including the inset shown in Figure 1d corroborate this asseveration. The shifting of these peaks towards higher and lower $2 \theta$ values, with respect to the pure $\beta-\mathrm{NiAl}$ and $\gamma-\mathrm{Ni}$ compounds is due to the multi-element composition of the powder. 
The chemical composition of the powder and used superalloys measured by EDS is given in Table II. The values of the nominal composition of Ta-containing NiCoCrAlY as well as the IN100, M247LC SX, and CMSX-4 superalloys are included as part of the same table [21,30,31]. It is well known that some elements, such as Ti, Ta, Mo, W, Hf and Re play an essential role in the diffusion processes of coated superalloys when exposed at high temperatures irrespective of the type of BC $[14,21,26]$. In the present cases, the main goal is to study the effects e.g., of Ta from the BC or specific elements from the substrates on the microstructural and chemical evolution of the TBCs through different processing steps. For instance, Ti and Mo contents are higher in IN100 compared to M247LC SX and CMSX-4. The Mo content is similar in M247LC SX and CMSX-4 superalloys. Tantalum can only be found in M247LC SX and CMSX-4 in different amounts. W and Hf contents are higher in M247LC SX than in CMSX-4 superalloy. Finally, rhenium is only present in the CMSX-4.

As a starting point, a set of typical micrographs of the substrates is shown in Figure 2. The microstructure of the three superalloys consists basically of $\gamma / \gamma^{\prime}$ phases, which are shown in the insets of the same figure. As expected, the IN100 presents (Ti, Mo)-rich carbides that are mostly formed along the grain boundaries (see Figure 2a). The M247LC SX consists of an in-house single crystalline-solidified alloy derived from the commercial directional-solidified Mar-M247LC superalloy. However, (Hf, Ta)-rich carbides are still observed in the microstructure as a result of the original composition of the alloy (Figure 2b). Finally, Figure 2c shows the typically expected microstructure of CMSX-4.

\subsection{Microstructure of the as-sprayed coatings}

Figure 3 shows XRD patterns of the coatings in the as-sprayed condition and after annealing, which are compared to the used original powder. The as-sprayed BC slightly changed the original $\beta / \gamma$ phases of the powder (Figure 3a). A peak broadening is observed as a consequence of micro-strains 
and/or grain refinement due to the rapid solidification of molten or semi-molten in-flight particles upon impact [32]. Moreover, the $\beta$ phase vanished from the XRD pattern, even when observed in high magnification micrographs. The reason is that in quenched molten droplets, rapid solidification does not allow its precipitation from a super-saturated $\gamma$ matrix [33].

In the case of the as-annealed $\mathrm{BC}$, a recrystallization process was observed, revealing the $\beta$ and $\gamma$ diffraction peaks. Additionally, the peak at $43.8^{\circ}$ evidences the presence of $\gamma^{\prime}$, which has been deconvoluted in Figure 3b. Mendis et al. [34] reported the formation of $\gamma^{\prime}$ in NiCoCrAlY during annealing at $1100{ }^{\circ} \mathrm{C}$ and subsequent air quenching. This $\beta \rightarrow \gamma / \gamma^{\prime}$ transformation takes place mainly as a consequence of $\mathrm{Al}$ diffusion $[11,12,34,35]$.

The as-sprayed bond coats, for the three studied cases, displayed the same initial microstructure. The thickness of the resulting bond coats is $\sim 180 \mu \mathrm{m}$ containing on average a porosity level of $7 \pm$ $0.8 \%$. The microstructural characteristics from the BC cross-section are shown in Figure 4, which is representative of the three studied cases. Figure 4a shows an overview of the as-sprayed bond coat deposited on the IN100 superalloy. In Figure 4b and 4c, the microstructures of the bond coats in the as-sprayed and as-annealed conditions are respectively compared. In the as-sprayed condition, the typical dendritic $\beta / \gamma$ phases microstructure from the powder is still observed. After annealing, the dendritic microstructure of the as-sprayed $\mathrm{BC}$ was modified to a $\beta$-layer $(\sim 3 \mu \mathrm{m}$ in thickness) on top of the coating and to a homogenous distribution of grains consisting of $\beta$ and $\gamma / \gamma^{\prime}$ phases through the coating thickness (Figure 4c). No alumina scale was formed during the annealing treatment. After EB-PVD top coat deposition, the aluminum contained in the $\beta$-phase layer oxidizes forming a dense $\alpha-\mathrm{Al}_{2} \mathrm{O}_{3}$ scale of $\sim 1 \mu \mathrm{m}$ in thickness (Figure $4 \mathrm{~d}$ ). Consequently, the formation of an aluminum depletion zone below the TGO is observed, which consists of a mixture of $\beta / \gamma^{\prime}$. As expected, the $\beta$-layer formation, $\beta / \gamma \rightarrow \beta / \gamma / \gamma^{\prime}$ transformation and TGO characteristics are similar for all types of substrates due to the homogeneous BC thickness $(\sim 180 \mu \mathrm{m})$. The 
diffusion processes are mainly manifested in microstructural changes along the SA/BC interfaces taking place during the annealing treatment prior to the 7YSZ EB-PVD deposition process. This effect is not surprising because of the intrinsic protective effect of the formed alumina scale during EB-PVD deposition. Therefore, changes in microstructure, particularly describing the formation of the so-called reaction diffusion layers as part of the well-known interdiffusion zone (IDZ) are presented and discussed, mainly for as-annealed samples for each type of SA (Figure 5).

In the coated IN100 superalloy, three reaction diffusion layers, two of them within the substrate and one within the $\mathrm{BC}$ are observed. Based on the EDS measurements, which will be further discussed in the section 3.4, the diffusion layers identified in the substrate consist of Al-enriched zones still coexisting with the $\gamma / \gamma^{\prime}$ microstructure. Close to the SA/BC interface $\left(I_{2}\right.$ zone in Figure 5a) in the first $\sim 5 \mu \mathrm{m}$, a rather fine-grained microstructure is observed (grain size of $4.3 \pm 0.6 \mu \mathrm{m}$ ). In the next $\sim 30 \mu \mathrm{m}$, a coarse-grained microstructure is found (grain size of $15 \pm 7 \mu \mathrm{m}$ ). Even though the $\gamma / \gamma^{\prime}$ microstructure size has not been measured, a coarsening effect of the $\gamma / \gamma^{\prime}$ microstructure in the $I_{3}$ zone is clearly observed. Within the $\mathrm{BC}, \mathrm{a} \sim 30 \mu \mathrm{m}$ reaction diffusion layer near to the $\mathrm{SA} / \mathrm{BC}$ interface is observed ( $I_{1}$ zone). This layer consists of an Al-depleted region and it is limited by the formation of $(\mathrm{Ti}, \mathrm{Ta})$-rich carbides as a result of interdiffusion of $\mathrm{Ti}$ and $\mathrm{Ta}$ from the $\mathrm{SA}$ and $\mathrm{BC}$, respectively (Figure 5a).

The observed microstructure in the BC on M247LC SX superalloy presents two reaction interdiffusion layers within both SA and BC, respectively (Figure 5b). The first layer within the $30 \mu \mathrm{m}$ of the SA from the SA/BC interface has been identified as the $M_{2}$ zone. This zone consists of enlarged aluminum enriched grains of around $11 \pm 5 \mu \mathrm{m}$. As for the sample with IN100 substrate, within the $\mathrm{BC}$ side, a $30 \mu \mathrm{m}$ thick $M_{1}$ zone formed by (Ti, Ta)-rich carbides is observed. Nevertheless, the carbides content observed along this BC is lower than in the case of the coated IN100. 
Finally, from the microstructure in the coated CMSX-4 superalloy, two reaction interdiffusion layers within the SA were identified (Figure 5c). The layer close to the SA/BC interface consists of grains of $9 \pm 3 \mu \mathrm{m}$ and (Re, W)-rich precipitates $\left(C_{1}\right.$ zone). A lower concentration of precipitates is observed in the second reaction diffusion layer ( $C_{2}$ zone), where grain boundaries are not yet clearly identified. It is well known that during the high temperature exposure, CMSX-4 tends to form TCP phases due to the content of Cr, Mo, W and Re [21]. Unlike the IN100 and M247LC SX cases, no precipitates are formed within the BC. After top coat deposition, in every studied case, the microstructure through the SA/BC interfaces clearly did not show changes.

Summarizing, in the as-annealed conditions the major content of (Ta, Ti)-rich carbides was formed in the BC with the IN100 superalloy followed by the M247LC SX. In the CMSX-4 system no precipitates were observed in the $\mathrm{BC}$. The average size of carbides in the $\mathrm{BC}$ is $0.8 \pm 0.2 \mu \mathrm{m}$, irrespective of the coated system.

\subsection{Microstructure of the coatings after furnace cyclic tests}

After 120 cycles at $1100^{\circ} \mathrm{C}$, typical micrographs showing the microstructure of the bond coats deposited on the different substrates focusing onto the interface $\mathrm{SA} / \mathrm{BC}$ are presented in Figure 6ac. All bond coats kept their porosity level at $\sim 7 \%$. However, the pores size grew after thermal exposure, probably associated to the Kirkendall effect. A set of micrographs shows details of the microstructure inside the reaction diffusion layers in Figure 6d-f, where precipitates are also observed. In fact, $(\mathrm{Ti}, \mathrm{Ta}) \mathrm{C}$ precipitates within the $\mathrm{BC}$ and reaction diffusion layer of the systems with IN100 and M247LC SX substrates are shown. Focused analysis with EBSD confirmed the type of carbides present in the as-sprayed condition. Typical indexed EBSD Kikuchi pattern is shown in Figure 6a. Again, the amount of (Ti, Ta)C formed within the BC on M247LC SX substrate was much less than those formed within the coating on IN100. After FCT, the size of carbides oscillates in the $1.6 \pm 0.5 \mu \mathrm{m}$ range, irrespective of the coated system. Further on, Figure 6c shows 
the formation of (Re, W)-rich TCP phases along the reaction diffusion layer formed on the CMSX4 substrate system. Within the $\mathrm{BC}$ on $\mathrm{CMSX}-4$ and as for the as-annealed condition no precipitates are observed.

In all cases, the formation of reaction diffusion layer ( $\sim 50 \mu \mathrm{m}$ in thickness) is observed within the SA as a consequence of the cyclic tests. For the coated IN100 the $I_{2}$ and $I_{3}$ zones from the assprayed condition (Figure 5a) led to a single layer ( $I_{4}$ zone) as shown in Figure 6a. The $I_{4}$ zone consists of equixially shaped grains, with intergranular ( $\mathrm{Ti}, \mathrm{Ta}$ )-rich carbides. For the coated M247LC SX system (Figure 6b and 6e) (Ti, Ta)-rich carbides are distributed in the microstructure of a $M_{3}$ zone in the BC. Additionally, in the SA side, close to the SA/BC interface (Hf, Ta)-carbides are formed. Finally, for the coated CMSX-4, Figure 6c and 6f shows (Re, W)-precipitates (TCP phases), which are distributed in the diffusion layer covering part of the SA.

\subsection{Evolution of chemical composition through the different processing steps}

\subsubsection{Phase identification from a normalization to a Ni-Al-Cr system}

Plotting the composition data measured by EDS in a Ni-Al-Cr ternary system following the site preference criteria of transition metals, reported by Jiang [29,36] allowed to predict the diffusion paths and thus the correspondent phase contents from the different processing conditions (Figures 7 and 8). Based on the mentioned site preference criteria the following normalization model at $1100{ }^{\circ} \mathrm{C}$ was used for $\mathrm{BC}$ and superalloys: $(\mathrm{Ni}+\mathrm{Co}+0.28 \mathrm{Mo}+\mathrm{Re})(\mathrm{Al}+\mathrm{Ti}+0.72 \mathrm{Mo}+\mathrm{Hf}+\mathrm{W}$

$+\mathrm{Ta})(\mathrm{Cr})[36]$. For instance, in the as-sprayed systems, Figure 7a shows the composition from the as-sprayed coatings in a $1100^{\circ} \mathrm{C}$ isothermal section of the Ni-Al-Cr ternary phase diagram, whereas the as-annealed system from coated IN100 superalloy is represented in Figure 7b. In the as-sprayed system and as expected, the $\mathrm{BC}^{\prime} \mathrm{s}$ are located within a $\beta+\gamma$ region and the three superalloys are within the $\gamma+\gamma^{\prime}$ region. After the annealing treatment, a diffusion process occurred within the BC 
showing how the top of the $\mathrm{BC}$ transforms to $\beta / \gamma / \gamma^{\prime}$, whereas close to the SA/BC interface the BC undergoes a phase transformation to $\gamma$ (Figure $7 \mathrm{~b})$.

The composition after FCT as a result of diffusion processes is shown in Figure 8 for the three systems. These results show that the phase transformations of the $\mathrm{BC}, \mathrm{SA}$ and reaction diffusion layers are practically the same in the three cases. The entire BC matrix consists of $\gamma$ phase and the SA of $\gamma / \gamma^{\prime}$. The reaction diffusion layer of the coated IN100 ( $I_{4}$ zone) consists of $\gamma$ phase. Further on, the reaction diffusion layers of the coated M247LC SX and CMSX-4 substrates $\left(M_{3}\right.$ and $C_{3}$ zones, respectively) show a transition from $\gamma / \gamma^{\prime}$ to $\gamma$ phase. These transformations, which exist thermodynamically in the ternary system, are in agreement with the microstructure observed in Figure 6.

\subsubsection{Composition profiles at the SA/BC interfaces: IN100 matrix}

Further analysis of the chemical composition at the SA/BC interfaces for the differently coated superalloys aims to provide information about the evolution of the composition attributable to the different processing steps or cyclic tests, especially on profiles either from the matrix or precipitates. A comparison of the composition profiles as a function of distance after the different processing and testing steps from the $\mathrm{SA} / \mathrm{BC}$ interface matrixes is discussed as follows.

Figure 9 shows the composition profile of IN100 coated with Ta-containing NiCoCrAlY after the different processing steps, i.e., as-sprayed, as-coated and after thermal cycling, all referred to the as-received conditions (powder and substrate). The primary goal of this comparison is to correlate variations in composition with the microstructural changes caused by elemental diffusion. In the figure, the straight lines denote the as-received conditions, while the triangles, squares, and circles indicate the composition profiles of the as-sprayed, as-coated, and after thermal cycling conditions, respectively, either empty or filled, depending on the specific elements in each graph. The data 
were collected from approx. $300 \mu \mathrm{m}$ into the SA through the as-sprayed SA/BC interface up to approx. $180 \mu \mathrm{m}$ in the $\mathrm{BC}$.

As expected, the composition along all bond coats in as-sprayed conditions remains constant and matches the values of the powder (Figure 9a-c). However, variations of chemical composition through the $\mathrm{SA}+\mathrm{BC}$ system after the following processing stages are discussed as follows.

Figure 9a shows Ni and Al profiles (major containing elements). After both, top coat deposition and FCT, the Ni content within the BC increases in average up to 46.4 and 49.6 at.\%, respectively, because of the diffusion from the SA to the BC. Ni diffusion is confirmed with the values observed after FCT in the range from -100 to $0 \mu \mathrm{m}$, where the Ni content decreases showing a gradient from 57.8 to 52.4 at. $\%$.

Similarly, Figure 9a shows variations in $\mathrm{Al}$ content within the $\mathrm{BC}$, which presented a gradient in the range of $16-10.8$ at.\% from the $\mathrm{BC}$ surface to the $\mathrm{SA} / \mathrm{BC}$ interface, as a result of the temperatures involved in the top coat deposition process. As expected, Al diffuses through the BC to the surface forming the alumina scale. The nearest zone to the TGO scale showed in average, in both $\beta$-layer and Al-depletion zone (previously shown Figure 4), an Al content of approx. 18 at. \%. The diffusion of Al to the substrate was also observed, where a slight increase of Al from 10.8 to 13.3 at. $\%$ is presented along with the $I_{2}$ and $I_{3}$ zones (range from -35 to $0 \mu \mathrm{m}$ ). After FCT, the Al depleted within the $\mathrm{BC}$, leading to values below to that of the SA ( $<11$ at.\%). Additionally, the $I_{4}$ zone reached the $\mathrm{Al}$ concentration of the SA and after this zone, an Al-enriched region of about 75 $\mu \mathrm{m}$ is formed.

Variations of other major-containing elements such as $\mathrm{Co}$ and $\mathrm{Cr}$ are shown in Figure $9 \mathrm{~b}$. After the top coat deposition, these elements presented variations not only in the average values but also in scattering, leading to average values from 21 to 17.5 at.\%, within the $\mathrm{BC}$ comparing with the as- 
sprayed condition. $\mathrm{Cr}$ is depleted in a $50 \mu \mathrm{m}$-thick layer starting from the outer surface of the bond coat in the as-coated condition, which may be associated to: 1) outwards diffusion leading to the formation and stabilization of an alumina scale during the EB-PVD process; 2) internal oxidation. Moreover, the $\mathrm{Cr}$ concentration within the $\mathrm{BC}$ after FCT showed a gradient with values still below the as-coated condition, from 18.9 to 16 at.\% (surface and interface, respectively). The increase of Cr from 10.3 to 15.3 at.\% observed within the $I_{4}$ zone from the SA, confirms that $\mathrm{Cr}$ also diffuses inwards.

Figure 9c shows that $\mathrm{Ti}$ and Mo have similar diffusion behavior into the $\mathrm{BC}$ matrix after top coat deposition presenting a slight increase in their concentration leading to $\sim 0.35$ at.\% within the first $25 \mu \mathrm{m}$ from the SA/BC interface into the BC. After FCT both elements show an increase in concentration within the $\mathrm{BC}$ reaching up to 1.0 at. $\%$ at the $\mathrm{SA} / \mathrm{BC}$ interface and 0.25 at. $\%$ at the BC surface. Those elements presented a decrease in the SA side, specifically in the $I_{4}$ zone, with a gradient from 4.2 to 1.2 at. $\%$ and from 1.5 to 0.9 at.\%, respectively. On the contrary, after FCT the Ta content decreased within the BC showing a gradient from 0.75 to 0.3 at.\% (surface and interface, respectively) below the as-coated condition. Finally, an increase of Ta up to 0.3 at.\% within the $I_{4}$ zone was noteworthy.

\subsubsection{Weibull distribution plots of minor-containing elements}

In general, chemical profiles along $\mathrm{BC}$ and $\mathrm{SA}$ showed similar behaviors in the $\mathrm{Ni}, \mathrm{Al}, \mathrm{Cr}$, and $\mathrm{Co}$ content after each processing step in the three cases of study. However, some of the minor containing elements $(\mathrm{Ti}, \mathrm{Ta}, \mathrm{Mo}, \mathrm{W}, \mathrm{Re})$ showed differences in diffusion processes with respect to the substrate, and it is worth to analyze them in more detail. A statistical interpretation of the chemical compositions for the three studied cases after furnace cycling tests can be facilitated plotting the values in Weibull distribution, especially to avoid data overlapping due to low

elemental contents. To do so, a two-parameter Weibull model was used to fit the composition 
profiles, based on the following equation, from which a Weibull distribution plot is obtained using the content of the mentioned elements in both the BC and SA sides:

$$
\text { Weibull factor }=\ln [\ln (1 /(1-p))]=m\left(\ln (x)-\ln \left(x_{0}\right)\right)
$$

where $p$ is the composition distribution for the measured elements ( $x=\mathrm{Ti}$, Ta, Mo, W, Re), $m$ is the slope of the Weibull plot, and $x_{0}$ is the scaling parameter and corresponds to the property of interest (elemental composition). Weibull plots are a useful tool since they also allow to separate highly scattered data. Thus, most of the elemental composition profiles especially from Ti, Ta, Mo, and $\mathrm{W}$ as the minor containing elements were plotted in Figure 10a-d after FCT from the bond coats and various superalloys. Hf and Re contents are represented in Figure 9e as composition profiles at the SA/BC interfaces from M247LC SX and CMSX-4 superalloys.

The elemental contents can be identified either from the substrates or the bond coats by their colors, where red corresponds to the bond coats and blue and black either the IDZ or SA, respectively.

For instance, titanium (Figure 10a) did not show variations compared to the as-received values from the three superalloys. Moreover, it is clear that outward Ti diffusion takes place (into the BC) from all substrates. However, considering that Ti content is higher in the series IN100 > CMSX$4>$ M247LC SX, after FCT the bond coats show contents proportional to those from their correspondent substrates so that the content in the BC on IN100 is up to 10 times higher than that on M247LC SX.

For tantalum and as part of the main objective of the paper, a combination of effects, depending on the content of the substrate can be observed (Figure 10b), leading to the following cases. Firstly, IN100 has nominally no Ta in its composition and accounts as the case with lower content than the BC, whereas M247LC-SX and CMSX-4 have either similar or higher Ta contents than in the BC, respectively. As a result of the three scenarios, in IN100 and M247LC SX substrates inward 
diffusion takes place (from the BC to the SA). However, in IN100, diffusion is limited to the IDZ leading to the formation of the $I_{4}$ zone, apparently defined by the Ta-content. Only in the M247LC SX, a homogeneous distribution of Ta was observed along both the substrate and bond coat. In these cases, tantalum diminution in the $\mathrm{BC}$ can be attributable to the following reasons: a) formation of Ta- or (Ta, Ti)-containing carbides or b) diffusion to the SA. An analysis of carbide precipitates composition with respect to the type of substrates will be discussed later. Finally and since the Ta content in CMSX-4 is higher than in the BC (2:1.2) an outward Ta-diffusion was expected. Surprisingly, it seems that no diffusion of Ta takes place in this substrate/BC combination at all. Only a more prominent scattering is observed from the SA side. Thus, the effect of suppressing Ti diffusion from the SA with the subsequent formation of (Ta, Ti)-containing carbides does not seem to be present in the CMSX-4, probably due to the presence of other elements such as Re, which itself shows high diffusion activity.

In the case of molybdenum, the highest content is observed in the IN100 superalloy (Figure 10c), which was previously discussed in Figure 9c. For the sake of comparison, a higher diffusion from IN100 into the BC (reaching 0.5 at.\%) than in the M247LC SX or CMSX-4 cases is noted. Bond coats deposited on M247LC SX and CMSX-4 substrates show similar Mo diffusion behavior, where in both cases a slight increment of Mo up to 0.2 at.\% in the BC was found.

Further on, tungsten is an element that is present only in the M247 LC SX and CMSX-4 substrates (Figure 10d). Apart from the reaction $M_{3}$ and $C_{3}$ zones, $\mathrm{W}$ remains at the initial concentration into the SA. Along these zones, the W concentration decreases from 3.8 and 2.4 at.\%, respectively, to $\sim 1.0$ at.\%. In the Weibull plot, a bimodal $\mathrm{W}$ distribution in the $\mathrm{BC}$ of both substrates is observed, where the 1.0 at. $\%$ of $\mathrm{W}$ decreases to 0.2 at. $\%$ and is due to diffusion processes from the SA to the BC. Finally, Hf and Re diffusion can only be analyzed on M247LC SX and CMSX-4, respectively (Figure 10e) and are presented as plots of Hf- or Re-content vs. distance from the SA/BC interface. 
Hf was neither detected in the BC matrix nor in the SA side at depths around $50 \mu \mathrm{m}$. Additionally, no hafnium oxides were observed. The lack of $\mathrm{Hf}$ in the $\mathrm{BC}$ and $M_{3}$ zone suggests that this element does not diffuse to the $\mathrm{BC}$ and mainly reacts with the Ta and $\mathrm{C}$ within the $M_{3}$ zone forming (Hf, Ta)C. On the other hand, a significant diffusion depth is observed for Re (approx. $200 \mu \mathrm{m})$ that covers SA and BC.

3.4.4. Composition profiles at the SA/BC interfaces: Precipitates from IN100 and M247LC $S X$

Finally, the composition profile of precipitates (carbides) as a function of distance from the SA/BC interface is discussed as follows. These measurements were carried out by point analysis directly on precipitates. Figure 11 shows the chemical composition of the carbides formed after FCT within the bond coats deposited on IN100 and M247LC SX superalloys (Figure 11a and 11b, respectively). Interestingly, these carbides also show a gradient in composition from the SA/BC interface to the $\mathrm{BC}$ surface, mainly in $\mathrm{Ti}$ and $\mathrm{Ta}$ content. The $\mathrm{Ti}$ content in the carbides in the coated IN100 has a tendency to decrease from 36.5 to 11.3 at.\%, whereas, Ta increases from 28 to 47.2 at.\% (Figure 11a). The carbon content in the precipitates remains as a balance between 35 and 40 at.\%. Based on the metal/carbon ratio, various metal-rich compounds appear to have stabilized. Thus, at the $\mathrm{SA} / \mathrm{BC}$ interface precipitates consisting of a $\left(\mathrm{Ta}_{0.45} \mathrm{Ti}_{0.55}\right)_{2} \mathrm{C}$ solid solution are formed, whereas at the surface, the $\mathrm{Ti} / \mathrm{Ta}$ ratio changes to $\left(\mathrm{Ta}_{0.8} \mathrm{Ti}_{0.2}\right) \mathrm{C}$ as a result of cyclic tests of the coated IN100 superalloy.

For the coated M247LC SX superalloy, the carbides composition seems to be more complicated, composed not only of $\mathrm{Ti}$ and $\mathrm{Ta}$, but also $\mathrm{Ni}$ and $\mathrm{Hf}$ (Figure 11b). For the Ti and Ta contents, a similar tendency is observed, as for the previous case, but with different gradients, in which $\mathrm{Ti}$ decreases from 15.4 to 0.95 at.\%, and Ta increases from 36.3 to 65 at.\%, whereas $\mathrm{Ni}$ and $\mathrm{Hf}$ decrease from 10 to 0.95 at.\%, and 9.0 to 1.0 at.\%, respectively. The carbon content in these 
precipitates remains in this system as a balance close to 30 at.\%. Thus, as for the last case, the composition of carbides is different at the interface and surface, namely $\left(\mathrm{Ta}_{0.52} \mathrm{Ti}_{0.22} \mathrm{Ni}_{0.12} \mathrm{Hf}_{0.14}\right)_{2} \mathrm{C}$ and $\left(\mathrm{Ta}_{0.9} \mathrm{Ti}_{0.02} \mathrm{Ni}_{0.06} \mathrm{Hf}_{0.02}\right)_{2} \mathrm{C}$, respectively.

A (Ta, Ti)C solid solution is formed as a result of Ti diffusion through the BC and occupancy in the Ta sites of a face-centered cubic TaC lattice. Fox et al. [20] proposed two sources of Ti either reaching the $\mathrm{BC}$ or forming $(\mathrm{Ta}, \mathrm{Ti}) \mathrm{C}$ precipitates. They claimed the possibility that, titanium which diffuses from the SA may be released during the formation of the IDZ when the $\gamma / \gamma^{\prime}$ of the superalloy structure transforms to a $\gamma / \beta$ structure considering that its solubility within the $\beta$ phase is less than it is in the $\gamma^{\prime}$ one. In this case, since the formation of a $\gamma / \beta$ structure within the SA was not observed, is not possible to confirm such asseveration. However, the second Ti source proposed is the fact to consider the SA as a bulk, which is practically limitless leading to high mobility through the BC. In the current case, the high mobility of Ti is confirmed by the results of chemical analysis from the matrix. It has been noted that oxidation resistance might be improved if the titanium supply is limited. In such a case carbides formation still serves as a mechanism to lower titanium chemical activity [20].

In this contribution, significant differences in carbides formation are observed. M247LC SX shows the lowest content of Ti and still tends to form carbides within the BC, whereas the coated CMSX4 has a higher Ti content but no carbides formation. This last result is surprising since in the work done by Goti et al. [19] "Ta-rich precipitates" are reported in NiCoCrAlYTa bond coats deposited by HVOF on a CMSX-4 superalloy. The hypothesis to this finding is that, even when Ti is diffusing to the NiCoCrAlYTa bond coat, the Ti-trapping effect by Ta seems to be achieved by the combination of the following effects:

a) Carbon present in the superalloy that will lead to the formation of (Ta, Ti)-containing carbides. In the case of CMSX-4 the carbon is absent in the nominal composition. 
b) The type of diffusion (inward or outward) as well as the gradient in $\mathrm{Ti}, \mathrm{Ta}, \mathrm{C}$ contents between the BC and SA seem to play a role. The different scenarios are as follows: 1) Ti always diffuses outward, 2) in IN100 and M247LC SX alloys, Ta diffuses inward, meanwhile no diffusion occurred in the CMSX-4 case, and 3) C, which is presented only in IN100 and M247LC SX diffuses outward.

Therefore, in CMSX-4, Ta does not show conditions to diffuse due to the $\mathrm{C}$ absence avoiding the Ti-trapping effect. IN100 and M247LC SX are carbon-containing alloys (nominally 0.81 and 0.35 at.\%, respectively) and at high temperature, the activity of carbon increases diffusing to the $\mathrm{BC}$. Moreover, the solubility of carbon in refractory metals increases as well and therefore, precipitation of metal carbides takes place $[37,38]$. Moreover, in the case of the coated CMSX-4, the diffusion of Re from the SA to the $\mathrm{BC}$ appears to limit the diffusion of $\mathrm{Ti}$ within the $\mathrm{BC}$ and to avoid the diffusion of Ta in both directions. These observations are consistent with other studies, which reported that Re additions in MCrAlY coatings suppress the elemental interdiffusion [39].

\section{Conclusions}

Relative Ta-contents from commercial Ta-containing NiCoCrAlY bond coat and three superalloys allowed to study different scenarios of inward / outward diffusion, not only of Ta but also of other elements from $\mathrm{BC}$ or superalloy and study their effect on the microstructure along the SA/BC after different processing conditions (as-sprayed, as-annealed, as-coated, and after furnace cyclic tests $\left(1100^{\circ} \mathrm{C} / 120 \mathrm{~h}\right)$ ). After furnace cycling, inward Ta-diffusion (from the BC to the SA) was observed in IN100 and M247LC SX. However, IN100 has a limited Ta-diffusivity whereas the M247LC SX reaches a homogeneous distribution of Ta along SA and BC. Tantalum forms carbides in different stoichiometries with other elements (Ti, Hf, Ni), depending on the SA composition, also driven by the C-content from SA. In the case of titanium from the IN100 and M247LC SX 
superalloys, it diffuses to the bond coat and forms carbides in solid solution with Ta in the bond coat. These carbides show a gradient from the bond coat/superalloy interface to the bond coat surface. ( $\left.\mathrm{Ta}_{0.45} \mathrm{Ti}_{0.55}\right)_{2} \mathrm{C}$ precipitates in solid solution are formed at the bond coat/superalloy interface, whereas at the surface the ratio changes to $\left(\mathrm{Ta}_{0.8} \mathrm{Ti}_{0.2}\right) \mathrm{C}$ as a result of cyclic tests of the coated IN100 superalloy. For the coated M247LC SX superalloy, the carbides composition at the interface and surface are $\left(\mathrm{Ta}_{0.52} \mathrm{Ti}_{0.22} \mathrm{Ni}_{0.12} \mathrm{Hf}_{0.14}\right)_{2} \mathrm{C}$ and $\left(\mathrm{Ta}_{0.9} \mathrm{Ti}_{0.02} \mathrm{Ni}_{0.06} \mathrm{Hf}_{0.02}\right)_{2} \mathrm{C}$, respectively. In general, outward Ti and Mo diffusion depends mainly on their concentrations in the correspondent substrate leading to concentrations in the BC proportional to their content in the superalloy. In the case of Hf, it diffuses from superalloy through the bond coat but either it reacts with $\mathrm{C}$ leading to the formation of carbides solid solutions or oxidizes at grain boundaries or pores. No Hf was detected in the bond coat matrix. Finally, neither outward Ta-diffusion (from SA to BC) nor carbides formation was observed in the coated CMSX-4 system possibly due to either the presence of rhenium or lack of carbon.

\section{Acknowledgments}

This project received support from CONACyT. J.M.S. thanks CONACyT and the Alexander von Humboldt Foundation for financial support for research activities at the German Aerospace Center (DLR). This work has been carried out at High temperature and multifunctional coatings department at DLR, Metals and Alloys department of University of Bayreuth, and CENAPROT and LIDTRA national laboratories at Cinvestav-Queretaro. The authors thank D. Peters for EBPVD coating manufacture. 


\section{References}

[1] S. Bose, High Temperature Coatings, Elsevier Science \& Technology Books, 2007.

[2] R. Vassen, M.O. Jarligo, T. Steinke, D.E. Mack, D. Stoever, Overview on advanced thermal barrier coatings, Surf. Coatings Technol. $205 \quad$ (2010) 938-942. doi:10.1016/j.surfcoat.2010.08.151.

[3] D.R. Clarke, C.G. Levi, Materials Design for the Next Generation Thermal Barrier Coatings, Annu. Rev. Mater. Res. 33 (2003) 383-417. doi:10.1146/annurev.matsci.33.011403.113718.

[4] C.G. Levi, Emerging materials and processes for thermal barrier systems, Curr. Opin. Solid State Mater. Sci. 8 (2004) 77-91. doi:10.1016/j.cossms.2004.03.009.

[5] D.R. Clarke, M. Oechsner, N.P. Padture, Thermal-barrier coatings for more efficient gasturbine engines, MRS Bull. 37 (2012) 891-898. doi:10.1557/mrs.2012.232.

[6] M. Peters, C. Leyens, U. Schulz, W. a Kaysser, EB-PVD Thermal Barrier Coatings for Aeroengines and Gas Turbines, Adv. Eng. Mater. 3 (2001) 193-204. doi:10.1002/15272648(200104)3:4<193::AID-ADEM193>3.0.CO;2-U.

[7] N.P. Padture, M. Gell, E.H. Jordan, Thermal barrier coatings for gas-turbine engine applications., Science. 296 (2002) 280-4. doi:10.1126/science.1068609.

[8] J.R. Davis, Handbook of Thermal Spray Technology, ASM International, OH, 2004.

[9] T.S. Sidhu, S. Prakash, R.D. Agrawal, State of the Art of HVOF Coating Investigations - A Review, Mar. Technol. Soc. J. 39 (2005) 53-64. doi:10.4031/002533205787443908.

[10] R.J. Hecht, G.W. Goward, R.C. Elam, High Temperature NiCoCrAlY Coatings, 3,928,026, 1975.

[11] B.G. Mendis, K.J. Hemker, Thermal stability of microstructural phases in commercial NiCoCrAlY bond coats, Scr. Mater. 58 (2008) 255-258. doi:10.1016/j.scriptamat.2007.10.016.

[12] B. Baufeld, M. Schmücker, Microstructural evolution of a NiCoCrAlY coating on an IN100 substrate, Surf. Coatings Technol. 199 (2005) 49-56. doi:10.1016/j.surfcoat.2004.06.014.

[13] W.O. Soboyejo, P. Mensah, R. Diwan, J. Crowe, S. Akwaboa, High temperature oxidation interfacial growth kinetics in YSZ thermal barrier coatings with bond coatings of NiCoCrAlY with $0.25 \%$ Hf, Mater. Sci. Eng. A. 528 (2011) 2223-2230. doi:10.1016/j.msea.2010.11.066.

[14] G. Pulci, J. Tirilló, F. Marra, F. Sarasini, A. Bellucci, T. Valente, C. Bartuli, High temperature oxidation and microstructural evolution of modified MCrAly coatings, Metall. Mater. Trans. A. 45A (2014) 1401-1408. doi:10.1007/s11661-013-2086-z.

[15] A. Vande Put, M.-C. Lafont, D. Oquab, A. Raffaitin, D. Monceau, Effect of modification by $\mathrm{Pt}$ and manufacturing processes on the microstructure of two NiCoCrAlYTa bond coatings intended for thermal barrier system applications, Surf. Coatings Technol. 205 (2010) 717-727. doi:10.1016/j.surfcoat.2010.07.064.

[16] J.M. Veys, R. Mévrel, Coatings on the Mechanical Properties of CMSX-2 and, 88 (1987) 253-260.

[17] R. Mévrel, State of the art on high-temperature corrosion-resistant coatings, Mater. Sci. Eng. A. 120-121 (1989) 13-24. doi:10.1016/0921-5093(89)90713-2. 
[18] T.A. Taylor, D.F. Bettridge, Development of alloyed and dispersion-strengthened MCrAlY coatings, Surf. Coatings Technol. 86-87 (1996) 9-14. doi:10.1016/S0257-8972(96)029611 .

[19] R. Goti, M. Bétaille-Francoual, E. Hourcastagné, B. Viguier, F. Crabos, Isothermal oxidation behaviour of NiCoCrAlYTa coatings produced by HVOF spraying and tribomet ${ }^{\mathrm{TM}}$ process, Oxid. Met. 81 (2014) 105-113. doi:10.1007/s11085-013-9422-y.

[20] P. Fox, G.J. Tatlock, Effect of tantalum additions on oxidation of overlay coated superalloys, Mater. Sci. Technol. 5 (1989) 816-827. doi:10.1179/mst.1989.5.8.816.

[21] R.C. Reed, The superalloys, fundamentals and applications, 1st ed., Cambridge University Press, 2006.

[22] A. Vande Put, D. Monceau, D. Oquab, Cyclic thermogravimetry of TBC systems, Surf. Coatings Technol. 202 (2007) 665-669. doi:10.1016/j.surfcoat.2007.06.017.

[23] M.T. Pace, R.C. Thomson, J. Wells, Oxidation of MCrAlY coatings on Ni-based superalloys, Proc. Int. Symp. Superalloys. 2 (2008) 651-660. doi:10.1179/174892408X373545.

[24] L.T. Wu, R.T. Wu, X. Zhao, P. Xiao, Microstructure parameters affecting interfacial adhesion of thermal barrier coatings by the EB-PVD method, Mater. Sci. Eng. A. 594 (2014) 193-202. doi:10.1016/j.msea.2013.11.054.

[25] Y. Itoh, M. Tamura, Reaction Diffusion Behaviors for Interface Between Ni-Based Super Alloys and Vacuum Plasma Sprayed MCrAIY Coatings, Trans. ASME. 121 (1999) 476483. doi: $10.1115 / 1.2818497$.

[26] K. Yuan, R.L. Peng, X.H. Li, A Continuous $\beta$-NiAl Layer Forming at the Interface of a MCrAlY and CMSX-4, J. Therm. Spray Technol. 25 (2016) 244-251. doi:10.1007/s11666015-0293-4.

[27] D. Seo, K. Ogawa, Y. Suzuki, K. Ichimura, T. Shoji, S. Murata, Comparative study on oxidation behavior of selected MCrAlY coatings by elemental concentration profile analysis, Appl. Surf. Sci. 255 (2008) 2581-2590. doi:10.1016/j.apsusc.2008.07.141.

[28] H. Ruíz-Luna, D. Lozano-Mandujano, J.M. Alvarado-Orozco, A. Valarezo, C.A. PoblanoSalas, L.G. Trápaga-Martínez, F.J. Espinoza-Beltrán, J. Muñoz-Saldaña, Effect of HVOF processing parameters on the properties of NiCoCrAlY coatings by design of experiments, J. Therm. Spray Technol. 23 (2014). doi:10.1007/s11666-014-0121-2.

[29] C. Jiang, Site preference of transition-metal elements in B2 NiAl: A comprehensive study, Acta Mater. 55 (2007) 4799-4806. doi:10.1016/j.actamat.2007.04.049.

[30] O. Metco, Thermal Spray Materials Guide, 2015.

[31] M. Bensch, C.H. Konrad, E. Fleischmann, C.M.F. Rae, U. Glatzel, Influence of oxidation on near-surface $\gamma^{\prime}$ fraction and resulting creep behaviour of single crystal Ni-base superalloy M247LC SX, Mater. Sci. Eng. A. 577 (2013) 179-188. doi:10.1016/j.msea.2013.04.032.

[32] A. Milanti, V. Matikainen, H. Koivuluoto, G. Bolelli, L. Lusvarghi, P. Vuoristo, Effect of spraying parameters on the microstructural and corrosion properties of HVAF-sprayed $\mathrm{Fe}-$ Cr-Ni-B-C coatings, Surf. Coatings Technol. 277 (2015) 81-90. doi:10.1016/j.surfcoat.2015.07.018.

[33] K. Fritscher, Y.-T. Lee, Investigation of an as-sprayed NiCoCrAlY overlay coating microstructure and evolution of the coating, Mater. Corros. 56 (2005) 5-14. 
doi:10.1002/maco.200403808.

[34] B.G. Mendis, B. Tryon, T.M. Pollock, K.J. Hemker, Microstructural observations of asprepared and thermal cycled NiCoCrAlY bond coats, Surf. Coatings Technol. 201 (2006) 3918-3925. doi:10.1016/j.surfcoat.2006.07.249.

[35] L. Ajdelsztajn, J. a. Picas, G.E. Kim, F.L. Bastian, J. Schoenung, V. Provenzano, Oxidation behavior of HVOF sprayed nanocrystalline NiCrAlY powder, Mater. Sci. Eng. A. 338 (2002) 33-43. doi:10.1016/S0921-5093(02)00008-4.

[36] J. Muñoz-Saldaña, U. Schulz, G.C. Mondragon-Rodriguez, L.A. Caceres-Diaz, H. Lau, Microstructure and lifetime of $\mathrm{Hf}$ or $\mathrm{Zr}$ doped sputtered NiAlCr bond coat / 7YSZ EB-PVD TBC systems, Surf. Coatings Technol. 335 (2018) 41-51. doi:10.1016/j.surfcoat.2017.12.017.

[37] L.E. Toth, Refractory Materials A Series of Monographs, Volume 7: Transition Metal Carbides and Nitrides, Academic Press, 1971.

[38] M. Durand-Charre, The Microstructure of Superalloys, CRC Press, 1998.

[39] W. Beele, N. Czech, W.J. Quadakkers, W. Stamm, Long-term oxidation tests on a Recontaining MCrAlY coating, Surf. Coatings Technol. 94-95 (1997) 41-45. doi:10.1016/S0257-8972(97)00473-8. 
Tables

Table I. HVOF spraying parameters used to produce bond coats

\begin{tabular}{ll}
\hline Parameter & Value \\
\hline Stand-off distance (mm) & 335 \\
$\mathrm{C}_{3} \mathrm{H}_{8}$ fuel flow (scfh) & 115 \\
$\mathrm{O}_{2}$ flow (scfh) & 303 \\
Air flow (scfh) & 434 \\
$\mathrm{~N}_{2}$ flow (scfh) & 355 \\
Fuel/Oxygen ratio & 0.3 \\
Powder feed rate (g/min) & 40 \\
Raster speed (m/min) & 60 \\
Number of passes & 10 \\
\hline
\end{tabular}


Table II. Nominal and measured chemical composition (at.\%) of powder and as-received superalloys.

\begin{tabular}{llcccccccccccc}
\hline Alloy & & Ni & Co & Cr & Al & Y & Ta & Ti & Mo & W & Hf & Re & C \\
\hline Amdry 997 & (Nom.) & 40.0 & 20.9 & 20.6 & 16.9 & 0.4 & 1.2 & - & - & - & - & - & - \\
& (Meas.) & 42.7 & 20.9 & 19.0 & 15.4 & 0.4 & 1.3 & - & - & - & - & - & - \\
IN100 & (Nom.) & 56.8 & 13.8 & 10.4 & 11.0 & - & - & 5.3 & 1.7 & - & - & - & 0.81 \\
& (Meas.) & 57.8 & 17.0 & 8.8 & 10.8 & - & - & 4.0 & 1.6 & - & - & - & - \\
M247LC SX & (Nom.) & 62.5 & 9.4 & 9.3 & 12.6 & - & 1.1 & 0.9 & 0.3 & 3.0 & 0.5 & - & 0.35 \\
& (Meas.) & 62.8 & 10.4 & 9.1 & 11.9 & - & 0.6 & 0.7 & 0.4 & 3.8 & 0.3 & - & - \\
CMSX-4 & (Nom.) & 62.9 & 9.9 & 7.6 & 12.6 & - & 2.2 & 1.3 & 0.4 & 2.1 & 0.03 & 1.0 & - \\
& (Meas.) & 62.1 & 11.6 & 6.4 & 12.6 & - & 2.2 & 1.2 & 0.4 & 2.4 & 0.0 & 1.1 & - \\
\hline
\end{tabular}




\section{Figures}
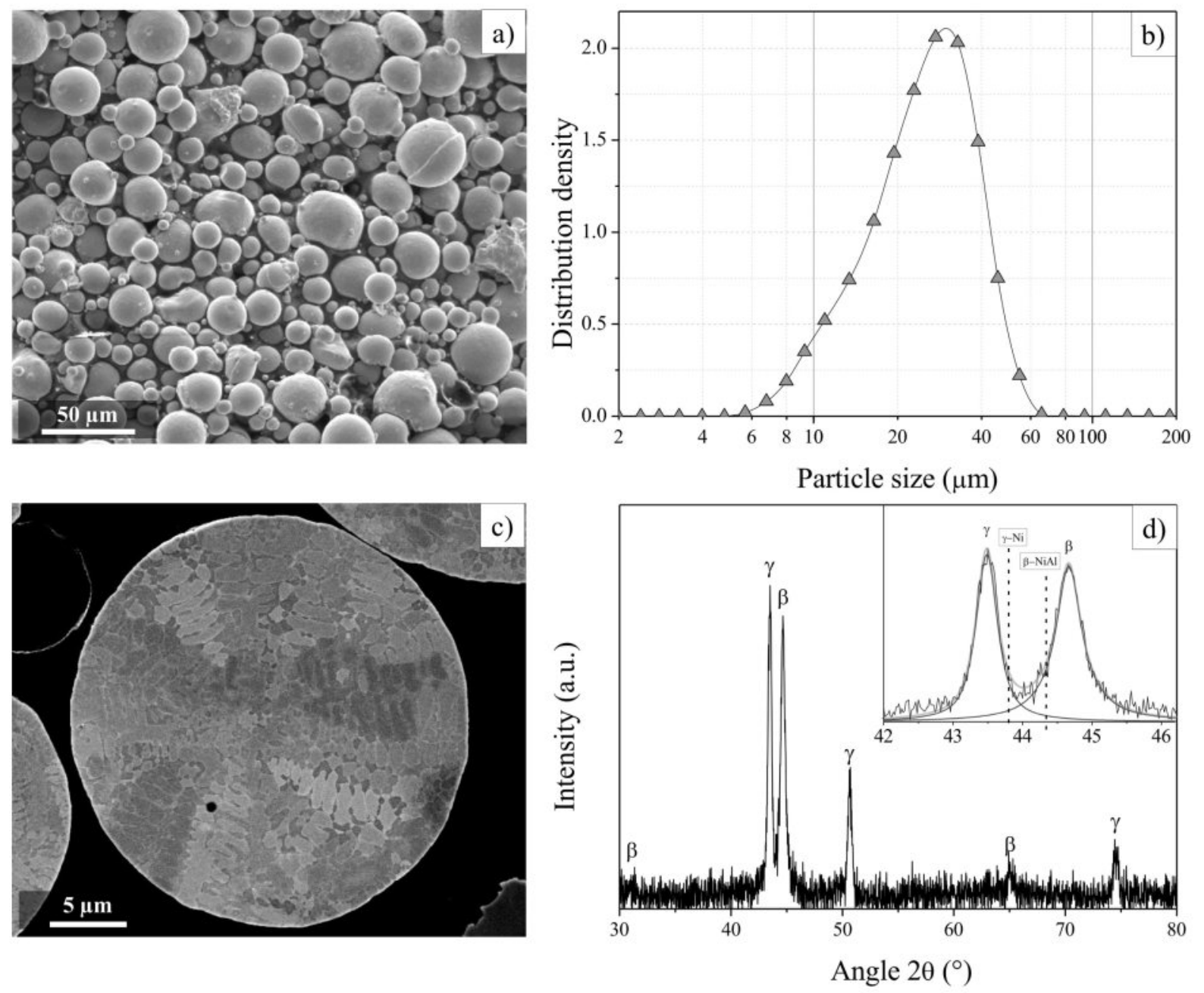

Figure 1 Microstructural characterization of as-received Ta-containing NiCoCrAlY raw material (Amdry 997) showing a a) micrograph with the powder morphology, b) particle size distribution, c) cross section of a single particle (backscattering detector) and d) XRD pattern. 


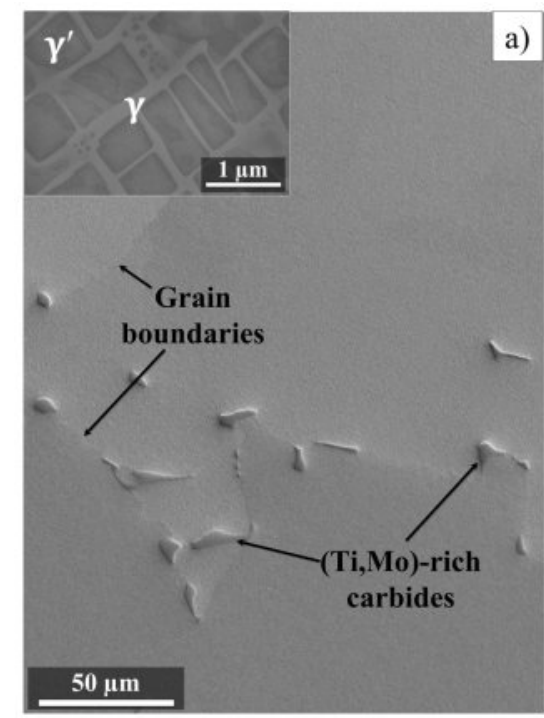

IN100

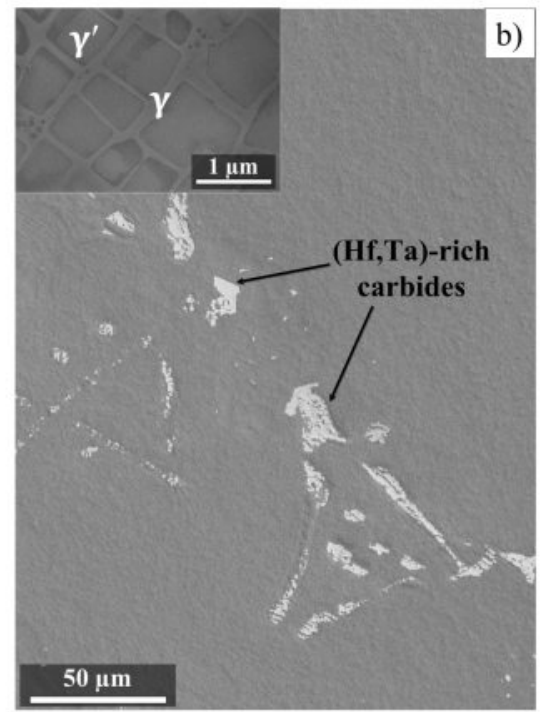

M247LC SX

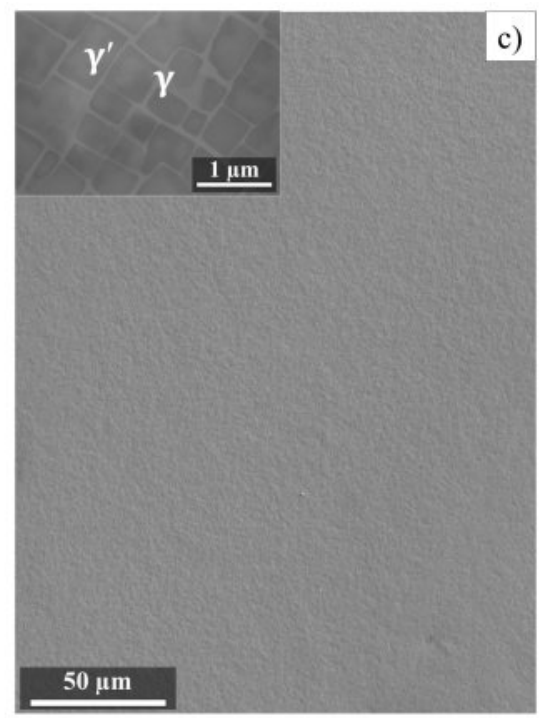

CMSX-4

Figure 2 Typical scanning electron micrographs from the used Ni-based superalloys a) IN100, b) M247LC SX, and c) CMSX-4 showing some characteristics, such as grain boundaries, precipitates, etc. The insets are micrographs recorded at higher magnifications showing the $\gamma / \gamma^{\prime}$ microstructure from each superalloy. 

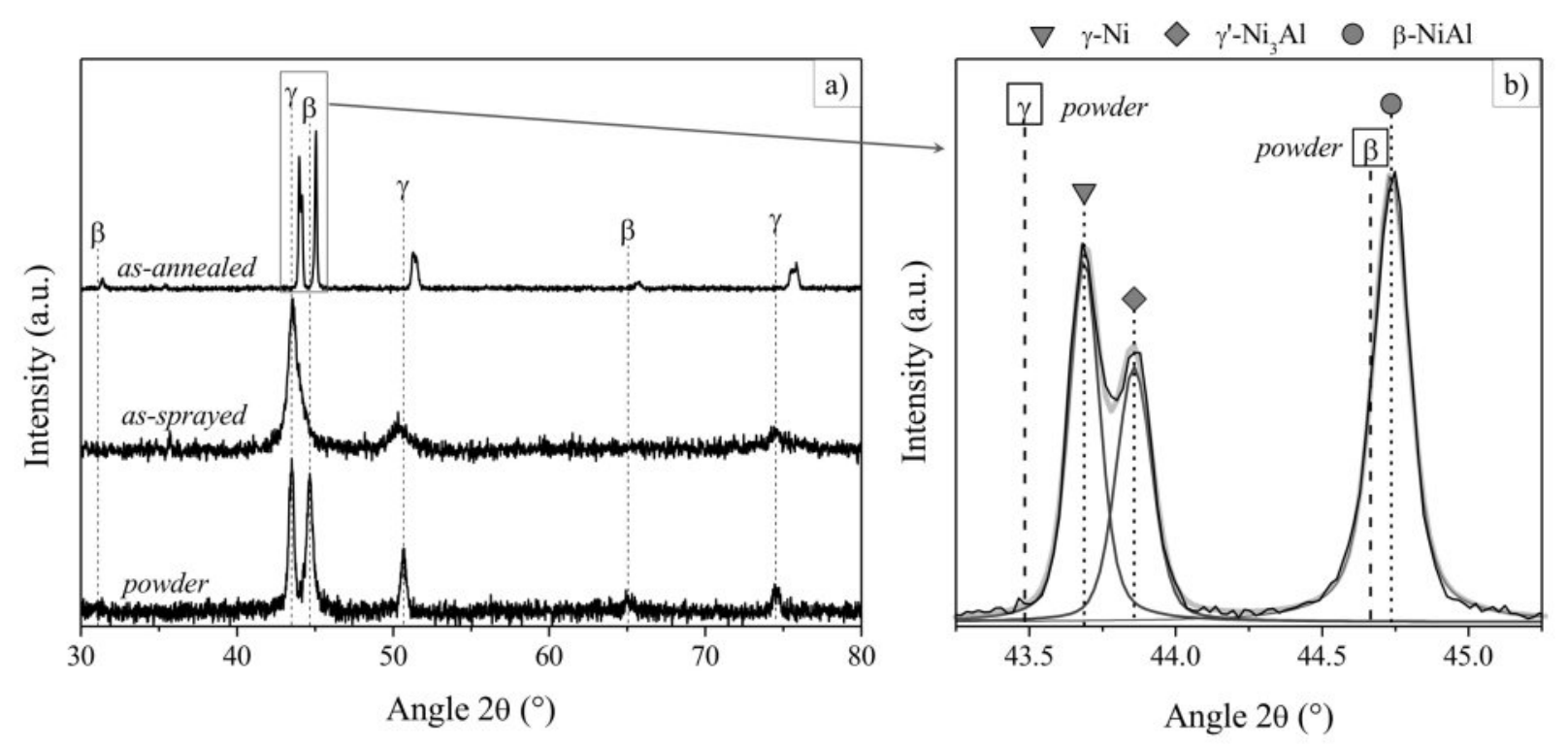

Figure 3 XRD patterns of the different stages of Ta-containing NiCoCrAlY deposition compared to raw material. b) Deconvolution of the main diffraction peaks from the as-annealed condition are also showing in the inset. 

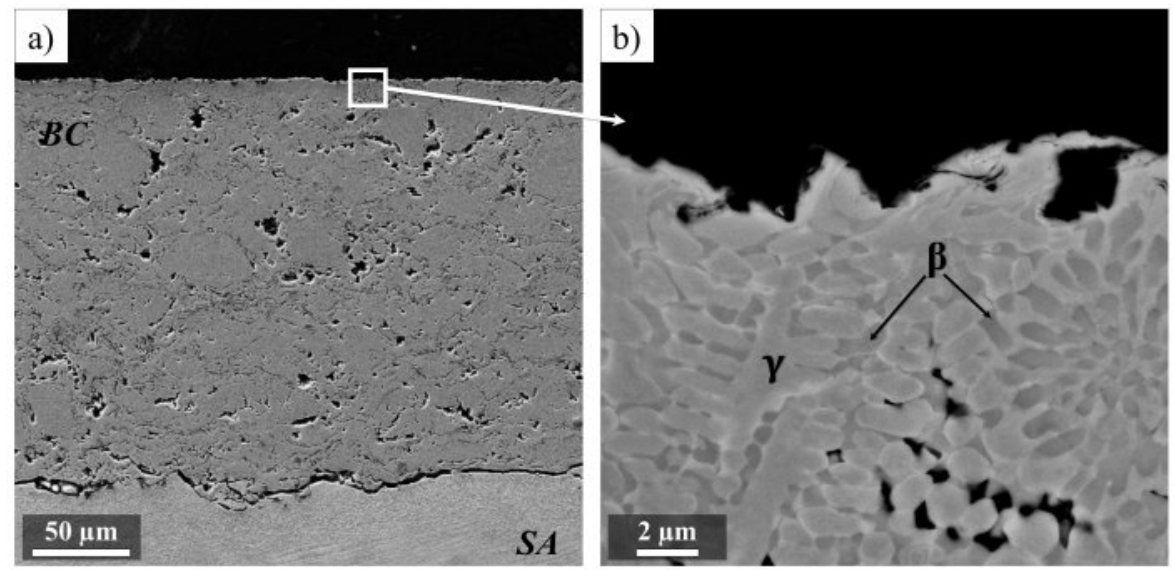

as-sprayed
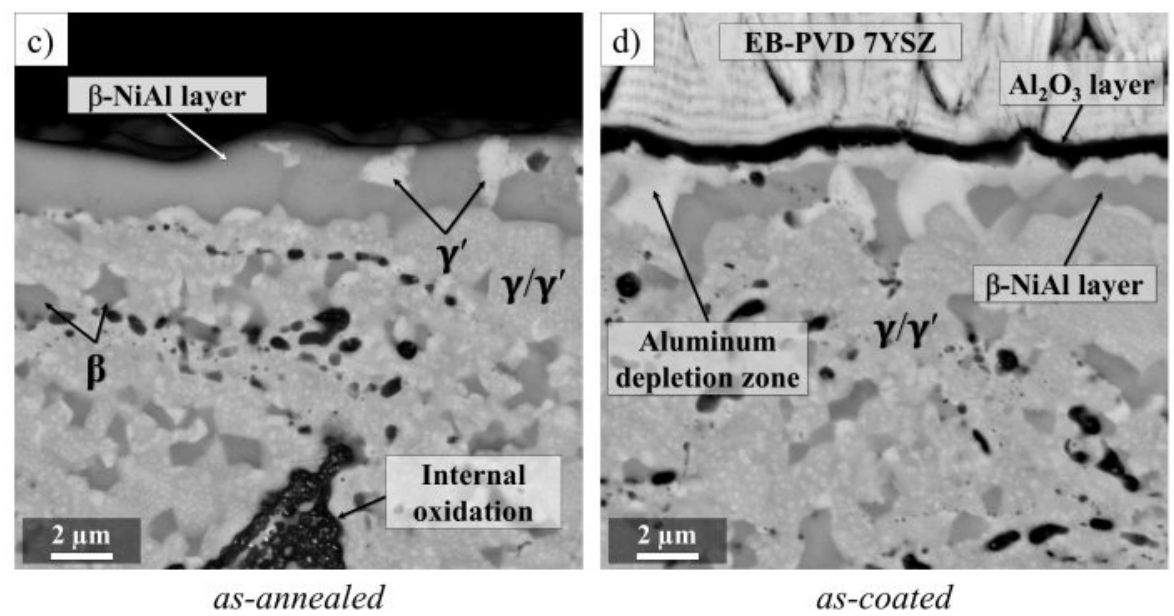

Figure 4 Evolution of the microstructural characteristics of the bond coat on IN100 substrate through the different processing stages; a-b) as-sprayed, c) as-annealed, d) as- top coated with 7YSZ-EB-PVD. 

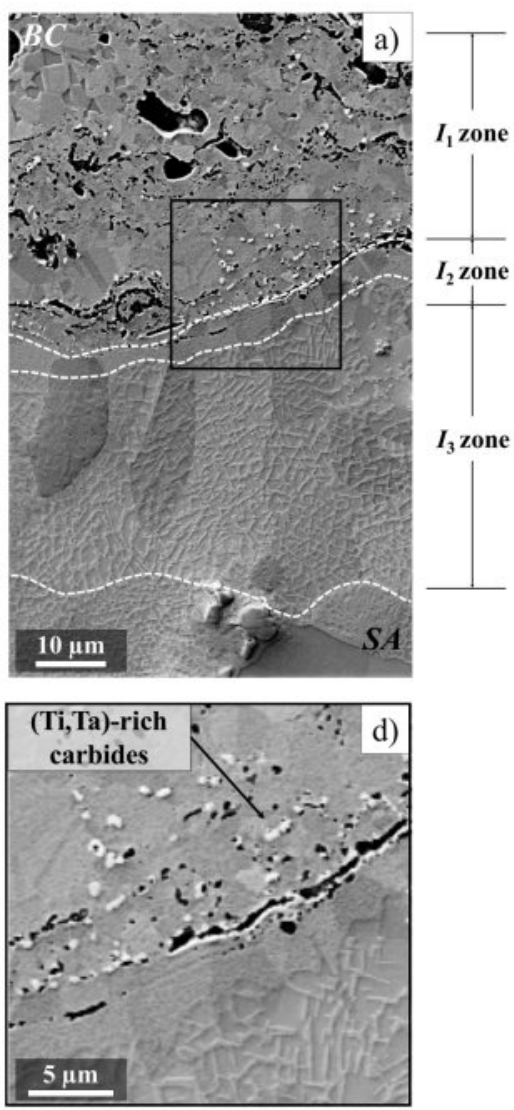

IN100 substrate
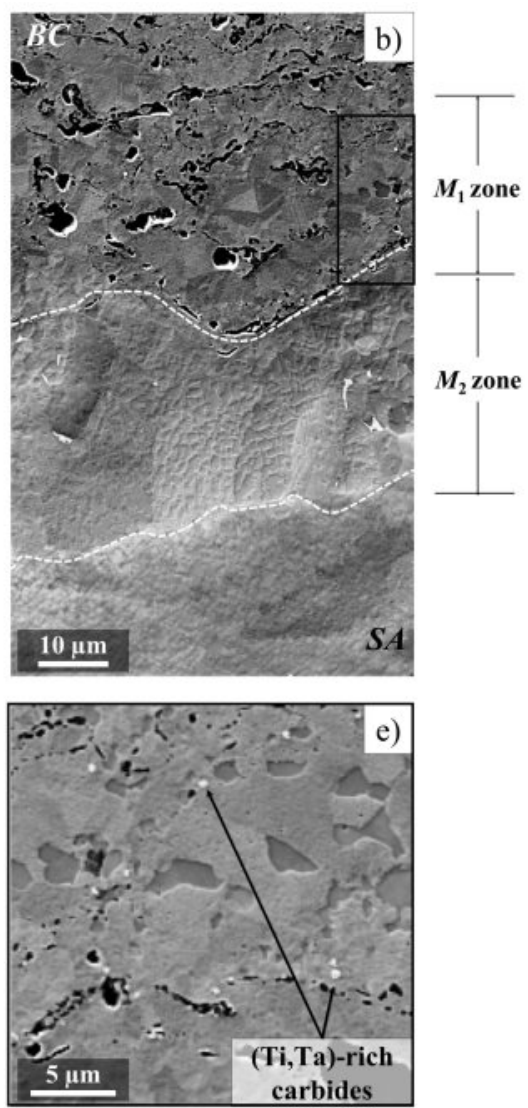

M247LC SX substrate
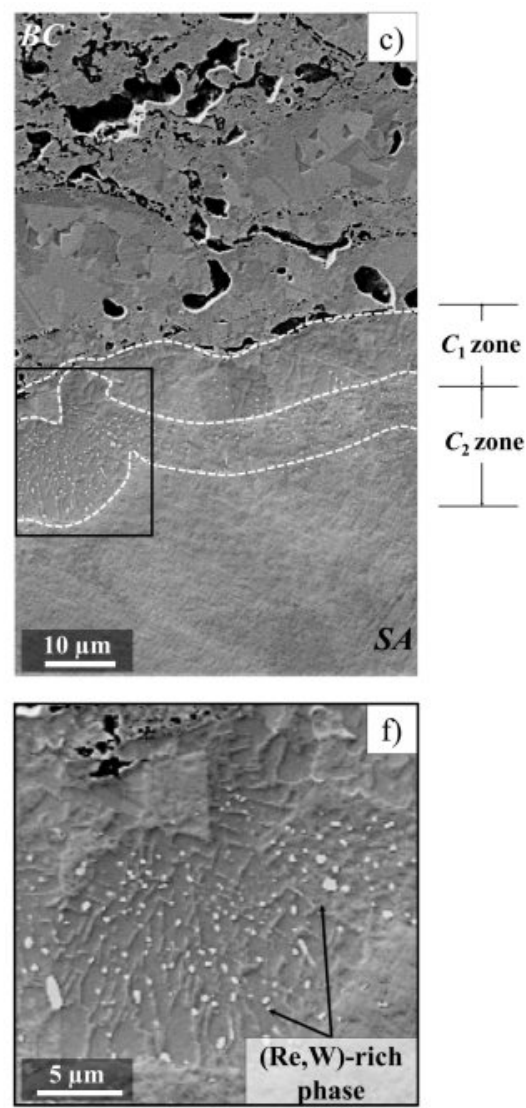

CMSX-4 substrate

Figure 5 Micrographs showing the reaction diffusion layer formed after of annealing treatment as function of each type of substrate: a) IN100, b) M247LC SX, and c) CMSX-4 substrate. d), e) and f) show the insets of the reaction diffusion layers indicated in a), b) and c), respectively. 

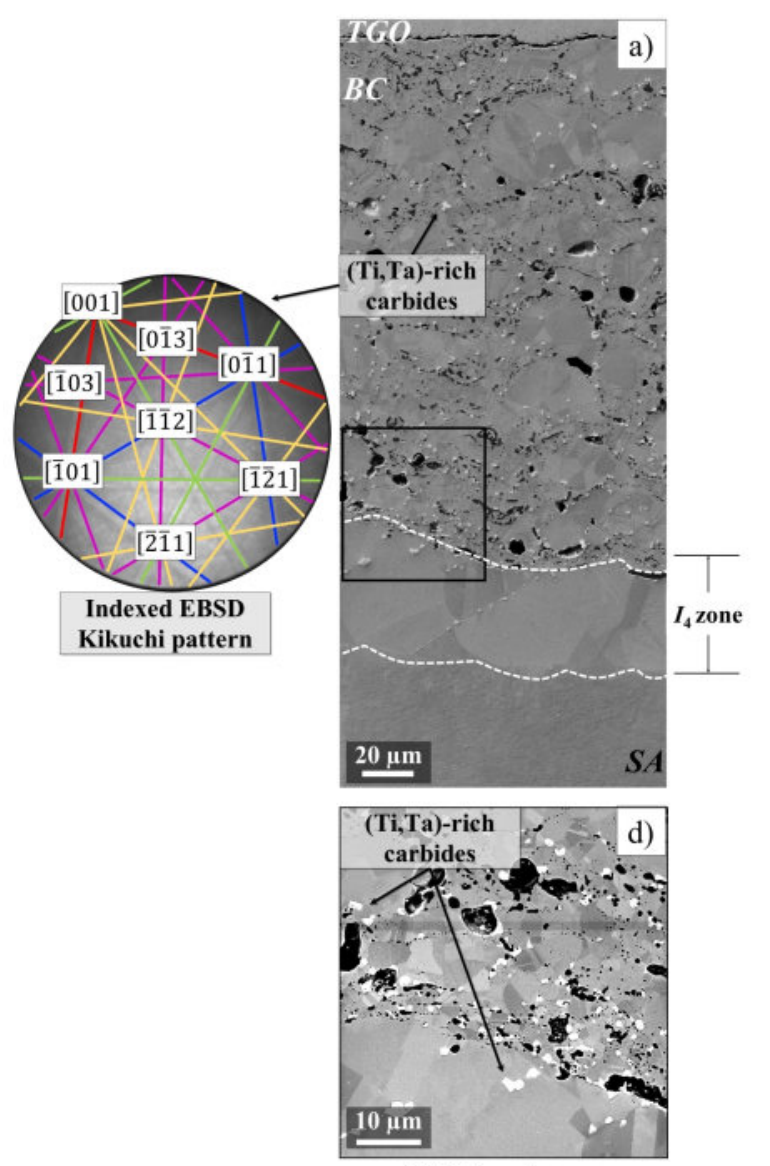

IN100 substrate
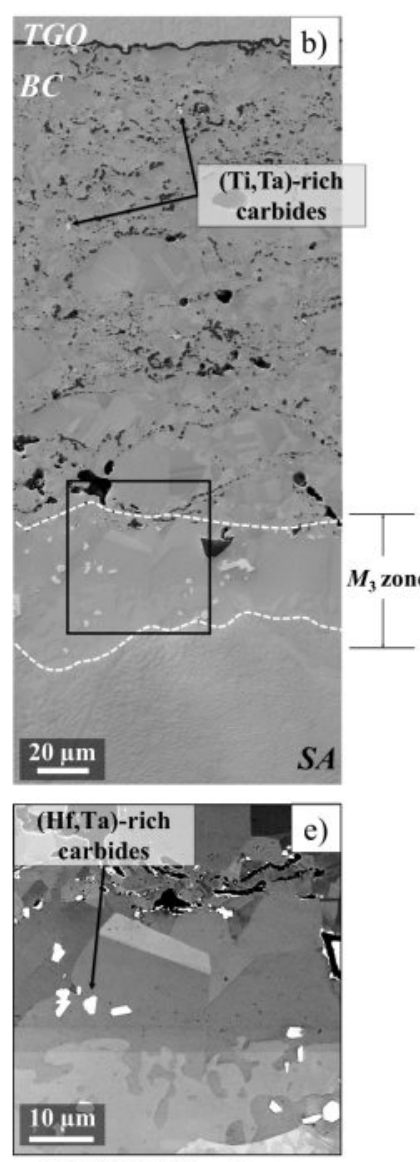

M247LC SX substrate
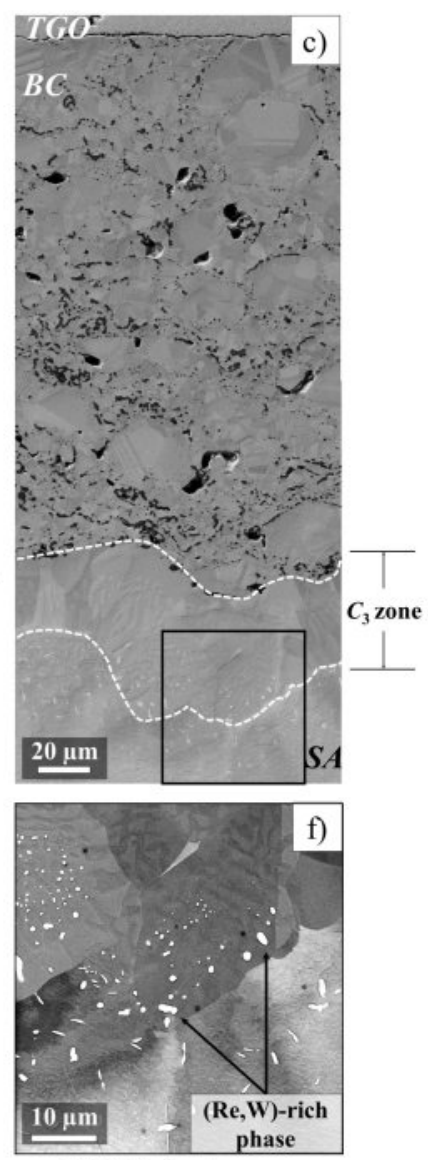

CMSX-4 substrate

Figure 6 Microstructures of bond coat after $120 \mathrm{~h}$ of thermal cycling: a) IN100, b) M247LC SX, and c) CMSX-4 substrates. d), e) and f) Insets from the reaction diffusion layers from each substrate. An indexed EBSD Kikuchi pattern corresponding to the observed (Ti, Ta)-rich carbides is also included. 
(a)

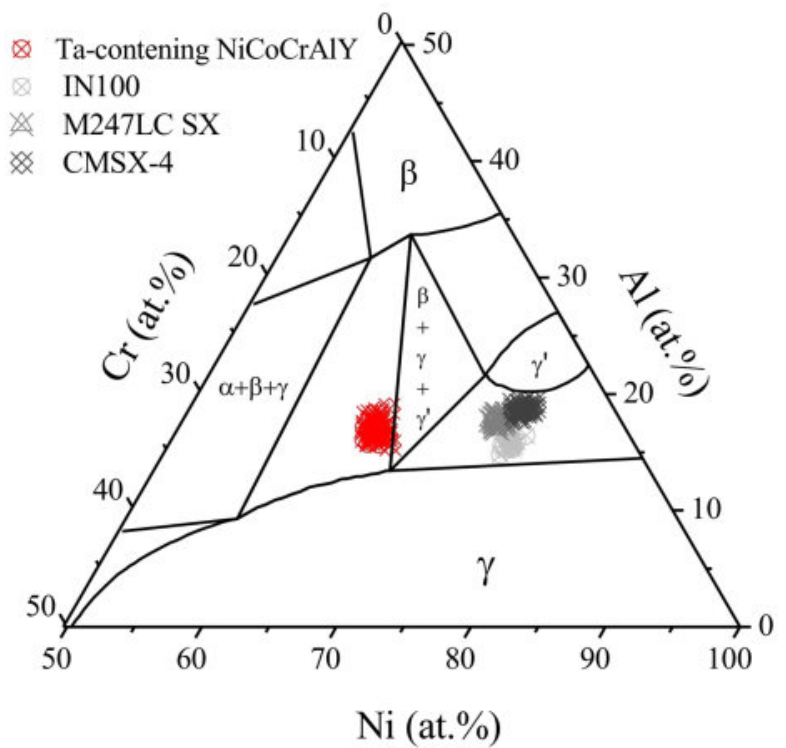

As-sprayed (b)

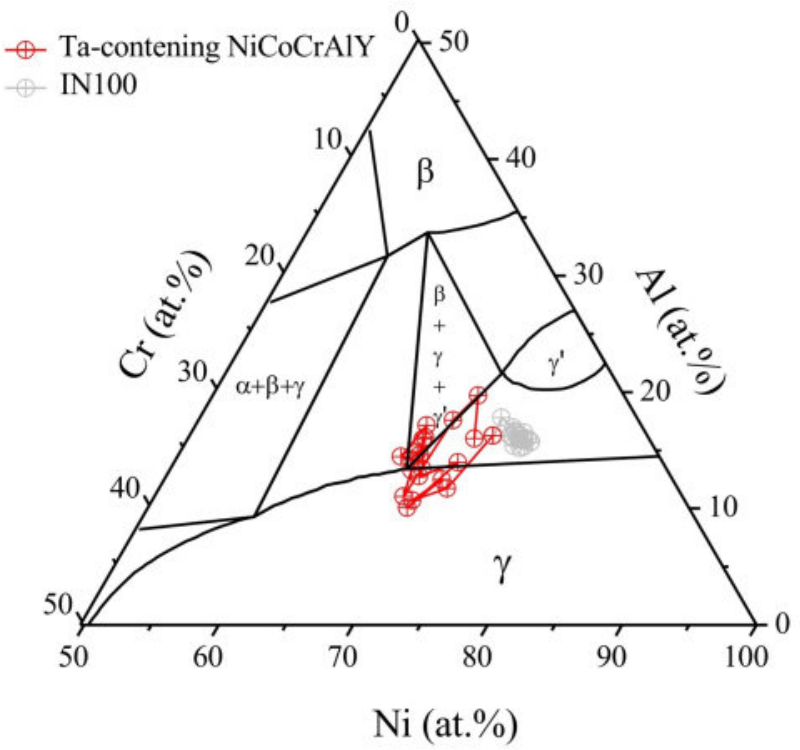

As-annealed

Figure $7 \mathrm{Ni}-\mathrm{Cr}-\mathrm{Al}$ phase diagram showing the plot of experimental EDS measurements from a) bond coat and used superalloys and b) diffusion path from $\beta / \gamma$-phase to the $\gamma / \gamma^{\prime}$ coating microstructure after annealing on the IN100 system.

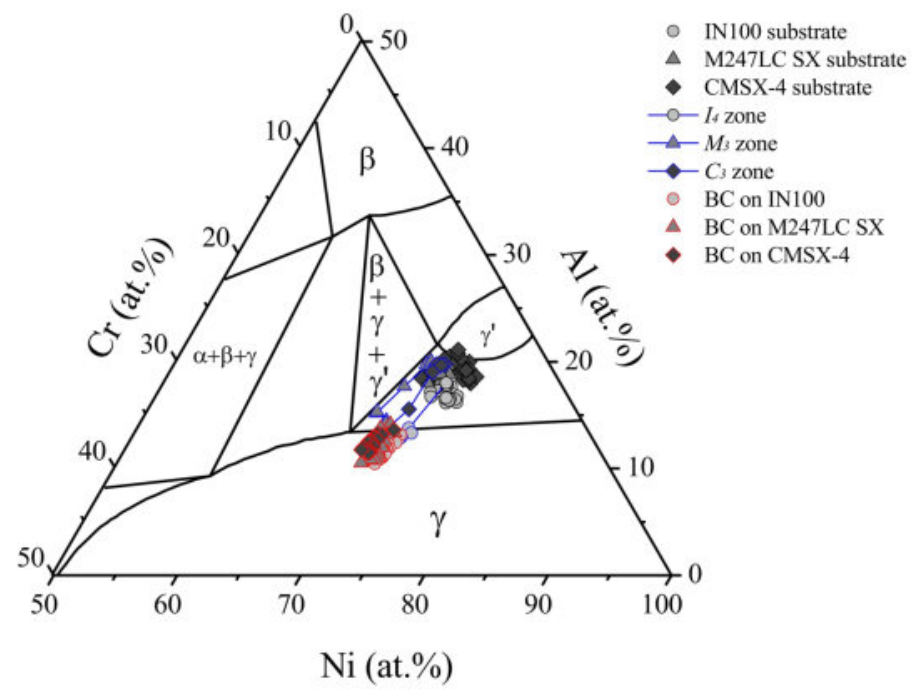

Figure $8 \mathrm{Ni}-\mathrm{Cr}-\mathrm{Al}$ phase diagram showing the diffusion path from the $\gamma / \gamma^{\prime}$ phase of superalloys IN100, M247LC SX, and CMSX-4 to the $\gamma$-phase bond coats after furnace cycling tests. 
(a)

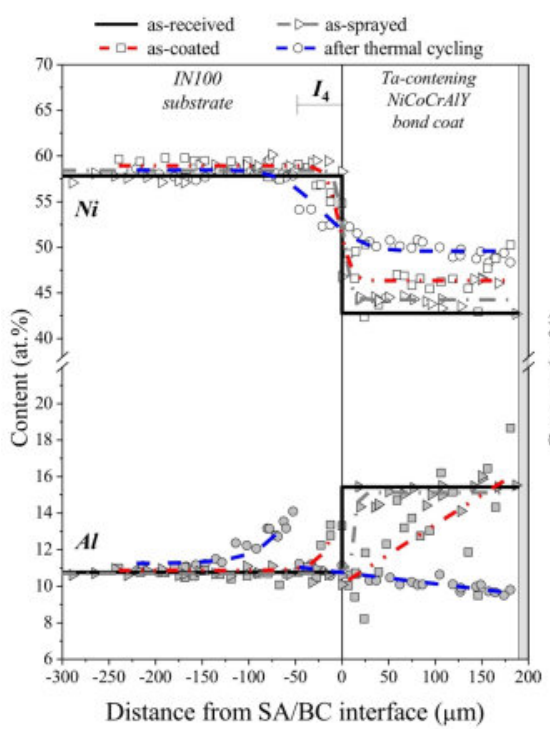

(b)

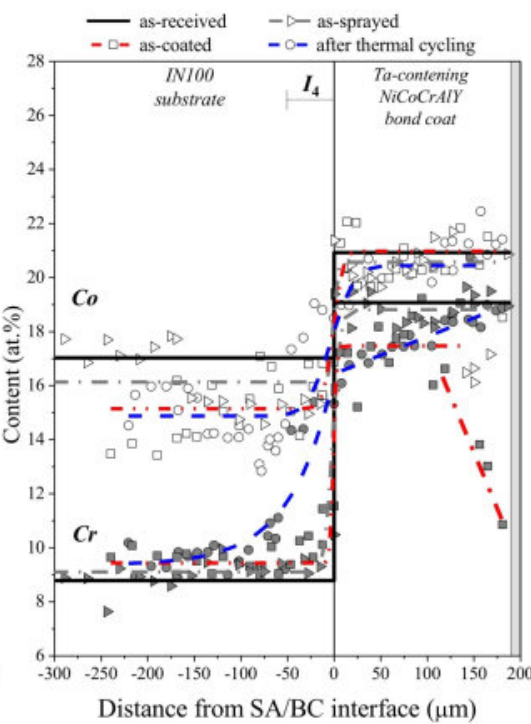

(c)

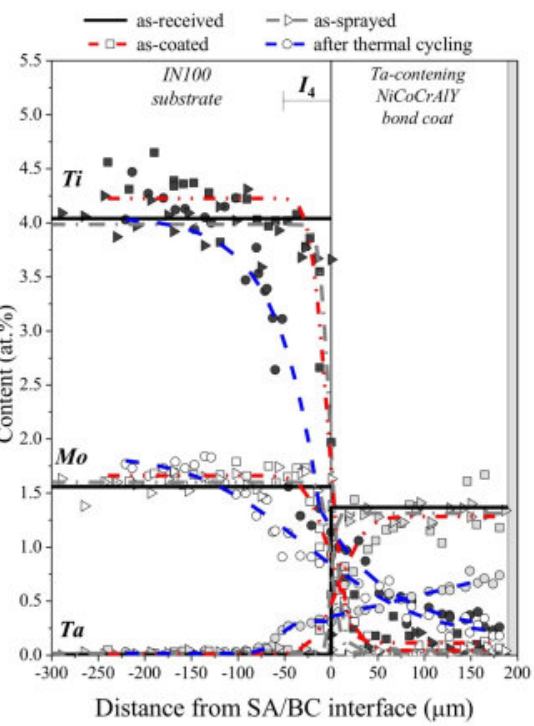

Figure 9 Chemical composition of IN100 superalloy coated with Ta-containing NiCoCrAlY after the different processing steps. Note that, in a), b), and c) the black lines shows the atomic content of every analyzed element in the as-received alloys, while the white, crossed and gray symbols indicates the content for as-sprayed, as-coated, and after thermal cycling conditions, respectively. 

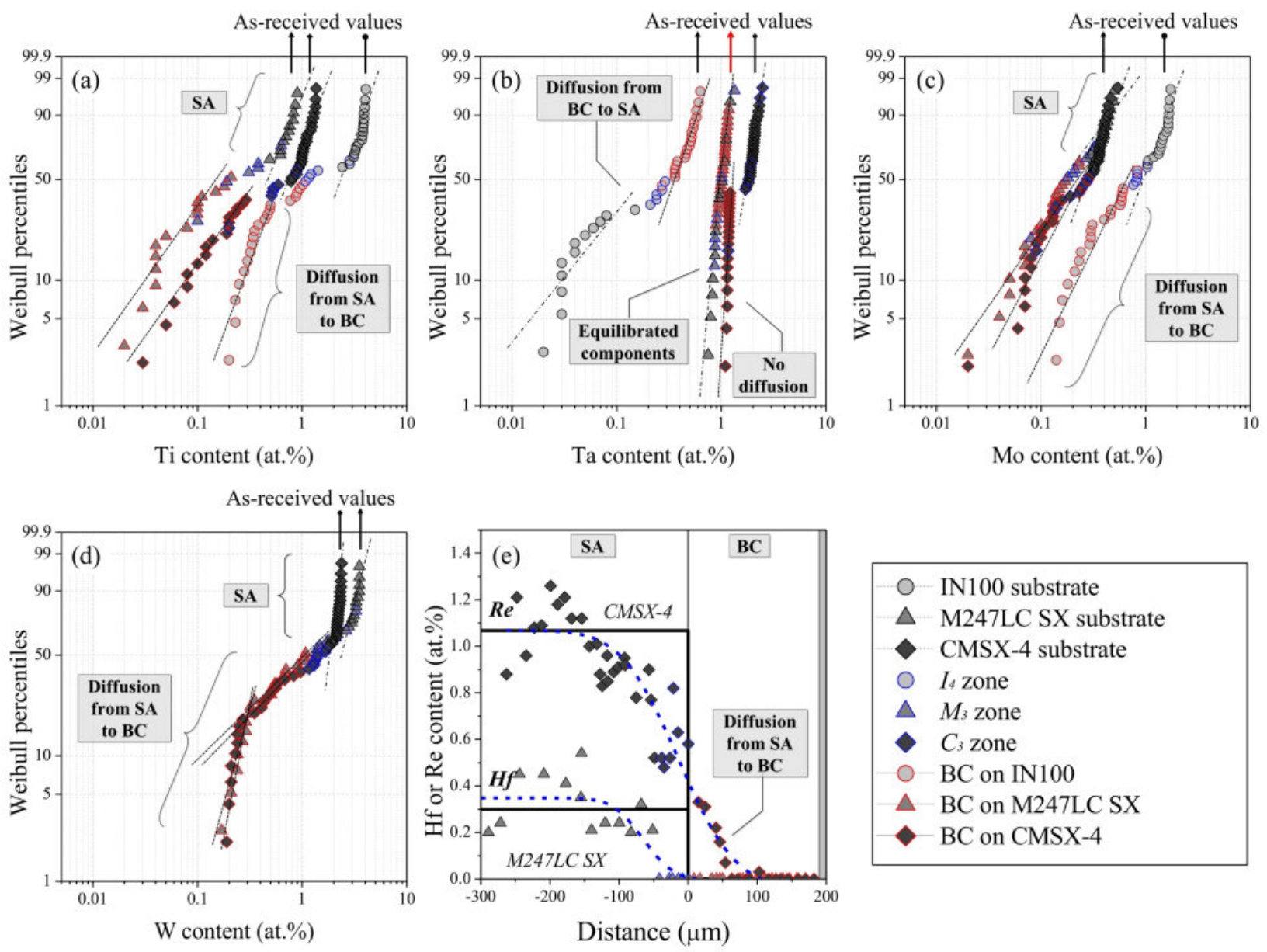

$\begin{array}{ll} & \text { IN100 substrate } \\ & \text { M247LC SX substrate } \\ \text { CMSX-4 substrate } \\ \quad I_{4} \text { Zone } \\ \quad M_{3} \text { zone } \\ \quad C_{3} \text { zone } \\ \text { BC on IN100 } \\ \text { BC on M247LC SX } \\ \text { BC on CMSX-4 }\end{array}$

Figure 10 Weibull distribution plots of minor elements [a) Ti, b) Ta, c) Mo, d) W] of the studied $\mathrm{BC}$ and substrates after thermal cycling. The correspondent $\mathrm{Hf}$ and $\mathrm{Re}(\mathrm{e})$ are represented as composition profiles at the SA/BC interfaces from CMSX-4 and M247LC SX superalloys. 
(a)

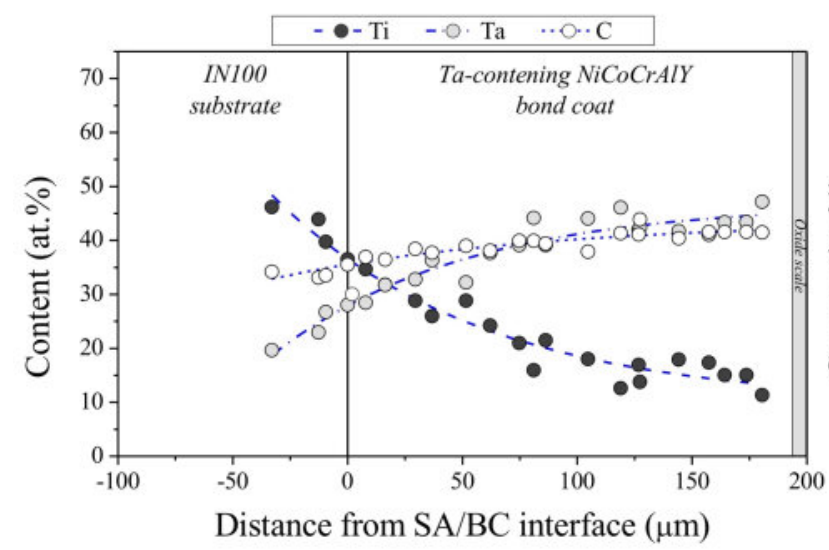

(b)

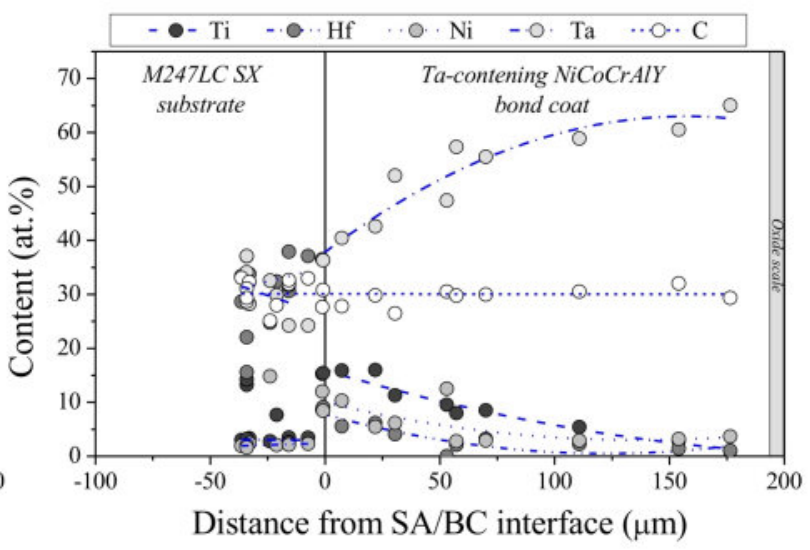

Figure 11 Chemical gradients of precipitates formed after thermal cycling in the bond coat with a) IN100 and b) M247LC SX substrates. No precipitates are observed in the coated CMSX4 system. 